\title{
"JUST SHOWING OUR CULTURE": LATINO/A STUDENTS CONSTRUCTING COUNTER-STORIES THROUGH BAILE FOLKLÓRICO
}

\author{
A Dissertation submitted to the faculty of \\ San Francisco State University \\ AS \\ 35 \\ 2016 \\ EDD \\ .944 \\ In partial fulfillment of \\ the requirements for \\ the Degree \\ Doctor of Education \\ In \\ Educational Leadership
}

by

Angela Kathleen Meeker

San Francisco, California

August 2016 
Copyright by

Angela Kathleen Meeker

2016 


\section{CERTIFICATION OF APPROVAL}

I certify that I have read "Just Showing Our Culture": Latino/a Students Constructing Counter-Stories Through Baile Folklórico by Angela Kathleen Meeker, and that in my opinion this work meets the criteria for approving a dissertation submitted in partial fulfillment of the requirement for the degree Doctor of Education in Educational Leadership at San Francisco State University

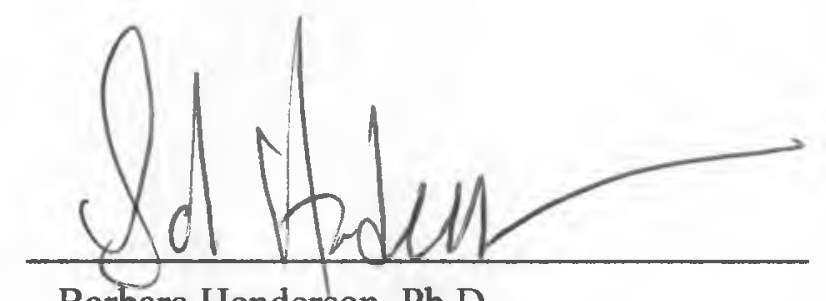

Barbara Henderson, Ph.D.

Professor of Education, SF State University

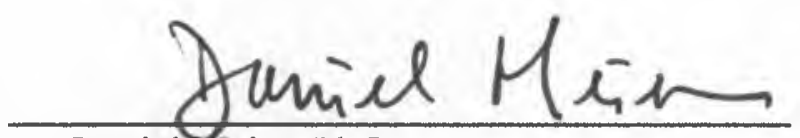

Daniel Mieier, Ph.D.

Professor of Education, SF State University

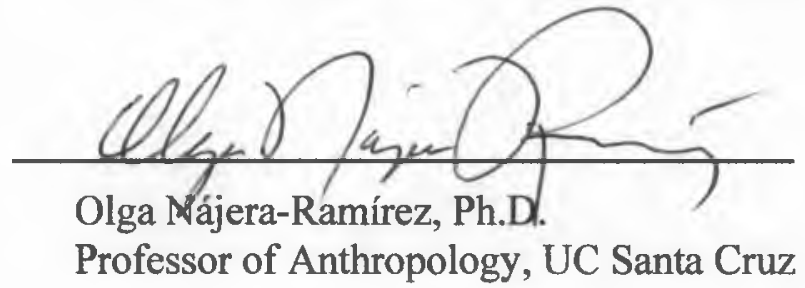




\section{ANGELA KATHLEEN MEEKER \\ San Francisco, California \\ 2016}

Latino/as represent the majority of students enrolled in K-12 education in California, yet they attend schools where the teaching population and curriculum choices do not reflect their culture. This study uses ethnographic methods to explore the experiences of 15 Latino/a students from ages 13 through 22 who participate in a Mexican folk dance group outside of school. Data from interviews and focus group sessions was coded through the theory of Community Cultural Wealth (Yosso, 2005) to determine how participants make sense of their involvement within this group and at school. The findings illustrate the impact of participation in cultural activity on students' recognition of cultural strengths, awareness of racism and a desire to create a counter narrative that promotes pride in their culture. These findings support recommendations for teacher training and curriculum development that will bolster an understanding of the assets Latino/a students bring and the importance of cultural activity to support equitable outcomes within and beyond the K-12 school system.

I certify that the Abstract is a correct representation of the content of this dissertation.

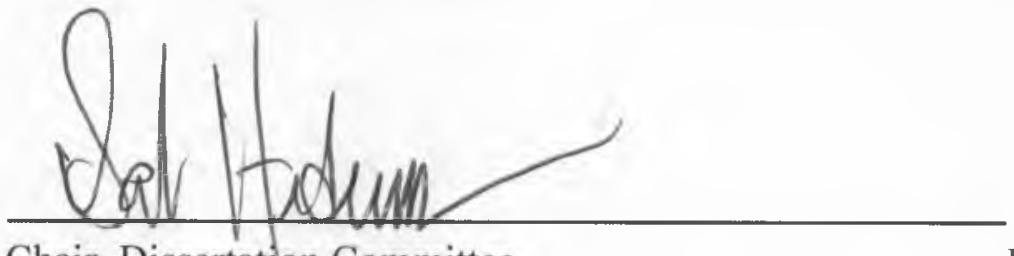




\section{ACKNOWLEDGMENTS}

This dissertation was inspired and supported by the community of Senderos. Their work stands as a testimonial to the power of cultural activity in building identity for students and awareness of the work we must do to achieve equitable outcomes. While dance is the outward expression of the group, the mission is to support Latino/a students by connecting them with their culture and providing them with tools for a better future in a society that does not value. Thank you to Fe, Nereida, Jenny and Chanel for giving so much time to this project; for opening the doors so I could attend practices and events. Thank you to my husband, Kurt, for listening, providing feedback and feeding me. To my children, Jillian and Gavin whose interest in social justice inspire me and make me proud! To my mother, Judy Flora, whose first grade classroom celebrated the language and culture of all her students. Thank you to my amazing chair, Dr. Barbara Henderson for her support and encouragement. She helped me through several significant changes to this work, keeping me focused on translation of this research to practice. Thank you to Daniel Meier for sharing key resources on arts in education and his excellent wordsmithing. I owe a huge debt of gratitude to Dr. Olga NájeraRamirez, whose personal narrative and research inspired the focus of this study. She helped me better understand how participation in folklorico is both aesthetic and identity. Finally, thank you to the students who shared their stories and their culture through interviews and dance. Their connection to who they are, their culture, and hope for a better future inspire us to do better. While schools cannot replicate the dance group, we can learn from their example and look to build bridges between the culture of students and the culture of school. 


\section{TABLE OF CONTENTS}

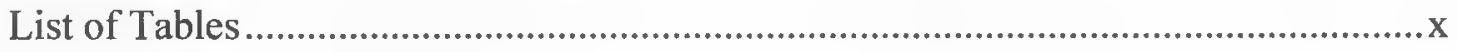

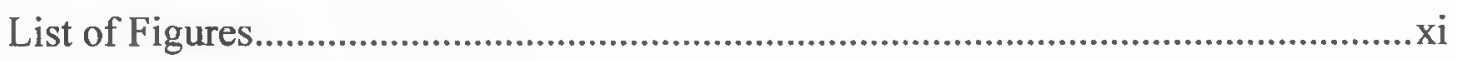

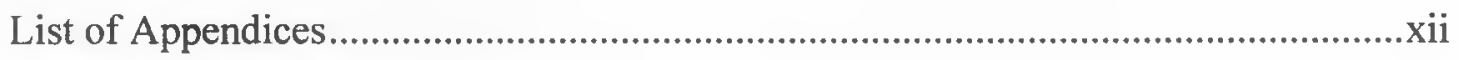

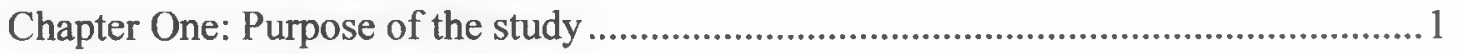

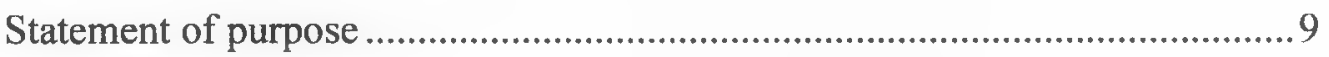

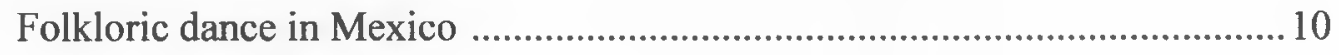

Folkloric dance in the United States...................................................... 12

Problem statement .............................................................................. 15

Research questions and proposition ................................................... 17

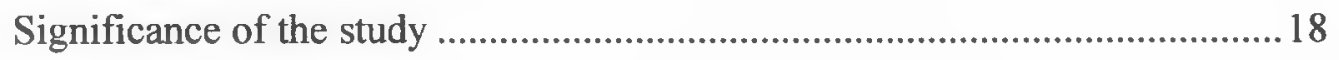

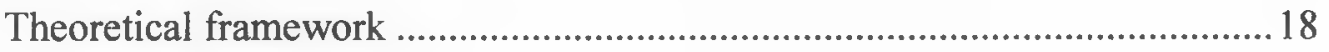

Community Cultural Wealth ................................................................. 19

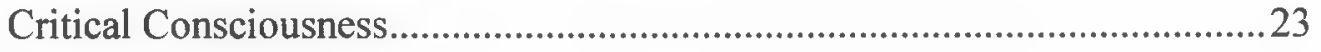

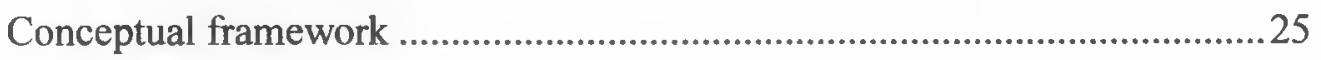

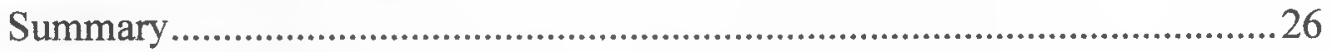

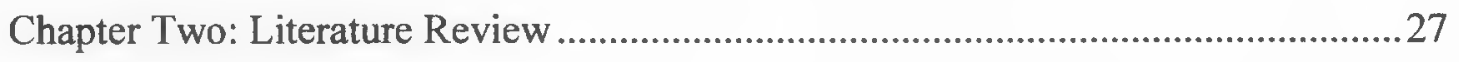

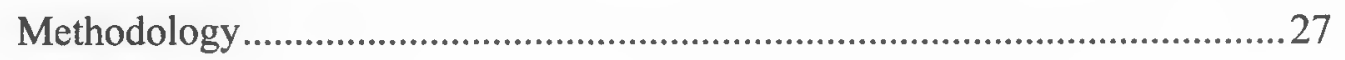

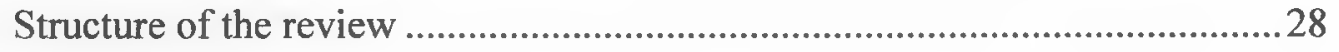

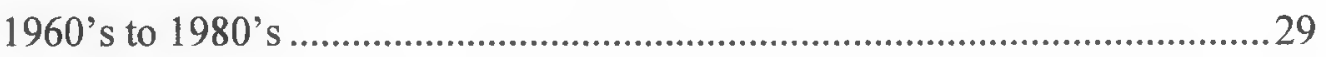

1980's to present: The Dismissive Movement ............................................. 32

Cultural activity and ethnic identity .....................................................3 34 
Ethnic identity 34

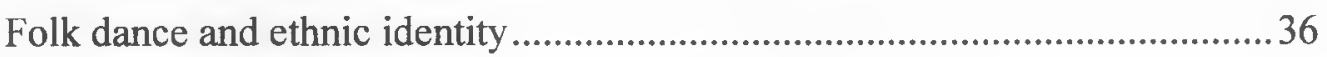

Folk dance, ethnic identity and counterspace ...........................................4 41

Ethnic identity development and student learning outcomes ........................4 43

Persistence and the opportunity gap .....................................................4 43

Social integration .........................................................................4 44

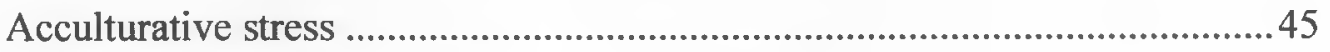

Ethnic identity and persistence in higher education ................................46

Ethnic identity and persistence in high school ...........................................49

Ethnic identity, academic achievement and engagement ............................51

Curriculum, ethnic identity and engagement...............................................5 52

Ethnic studies, academic achievement and engagement ...........................55

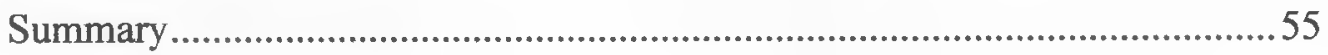

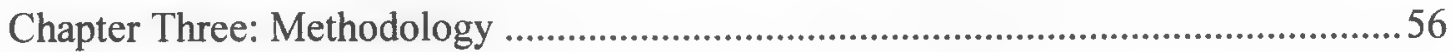

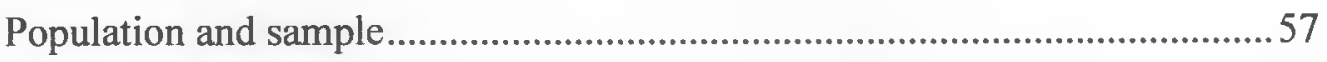

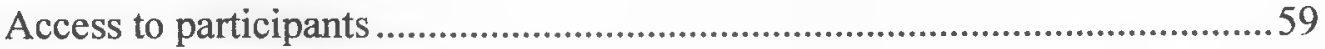

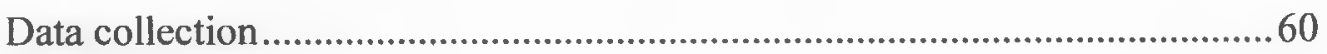

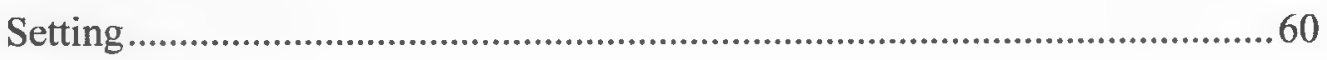

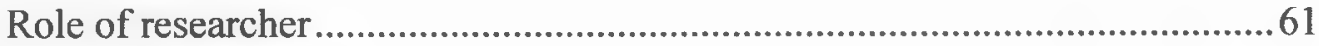

Data analysis procedures .............................................................6 63

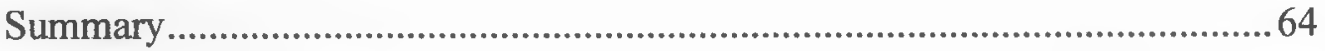

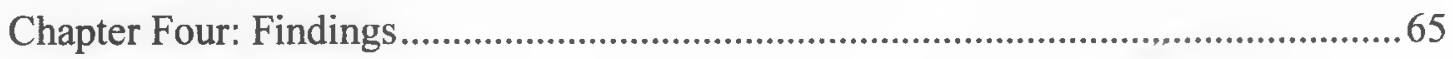




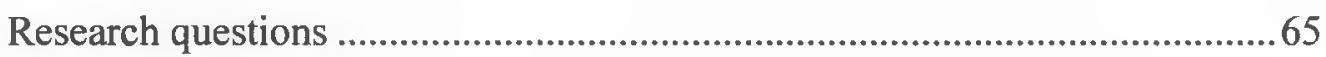

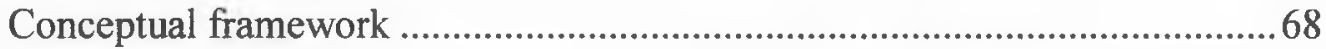

Dance practice as a culturally affirming environment........................................69

Physical space and comfort ............................................................................ 70

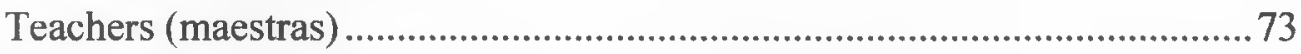

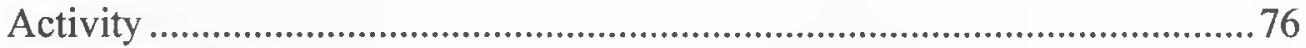

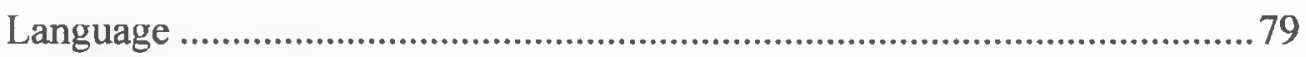

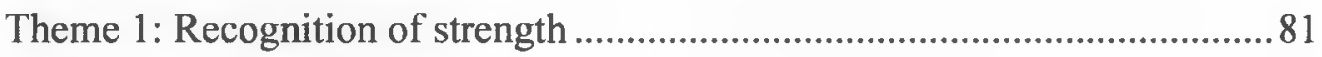

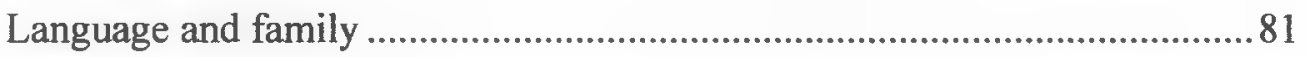

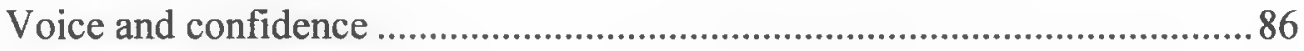

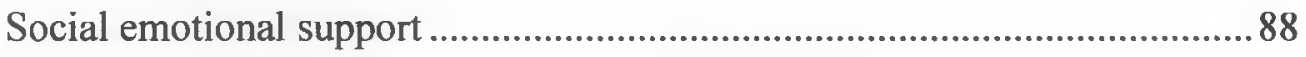

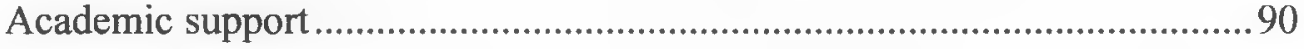

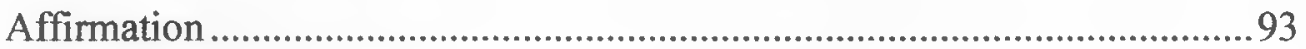

Theme 2: Rejection, indifference and inequity ..............................................95

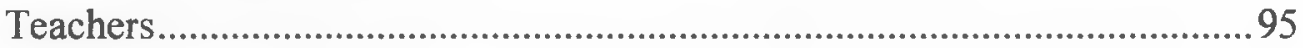

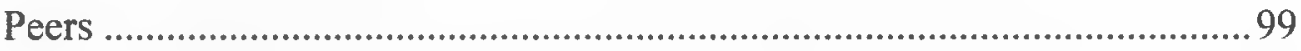

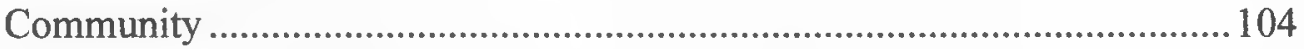

Theme 3: Identity and counter-stories ........................................................... 107

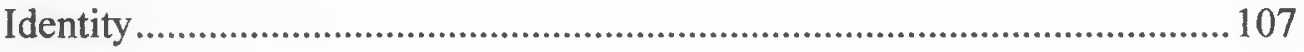

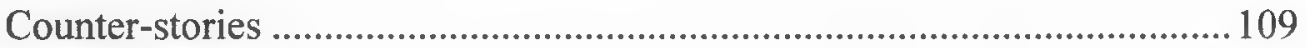

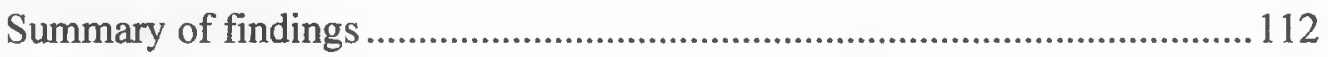

Chapter Five: Discussion and conclusions ............................................................ 118

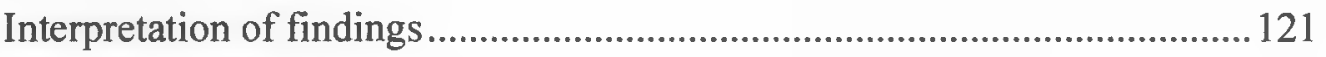


Implications and recommendations

Educational equity 125

Implications for curriculum and instructional program.

Recommendation 1: Revisions to curriculum 130

Recommendation 2: Biliteracy programs and master plan.

Implications for developing school culture

Recommendation 3: Profession development for counselors and teachers... 135

Recommendation 4: Goal setting to close the gap 136

Implications for community and school partnership

Recommendation 5: Partnership with community-based organizations ...... 137

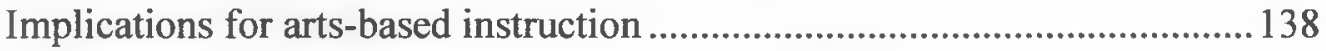

Recommendation 6: Increased access to cultural arts in schools ................. 139

Recommendations for further study ................................................. 140

Reflections on research process.......................................................... 141

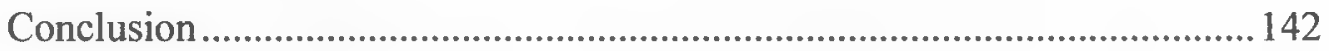

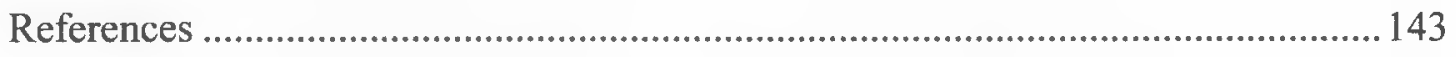

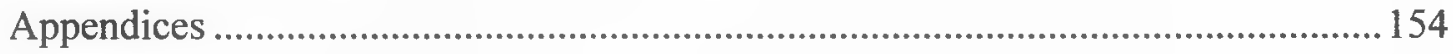




\section{LIST OF TABLES}

Table

Page

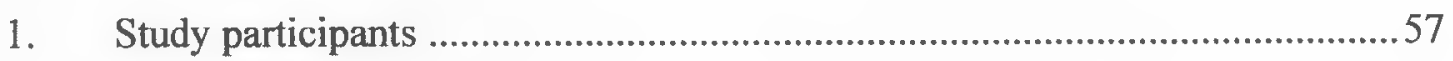




\section{LIST OF FIGURES}

Figure

Page

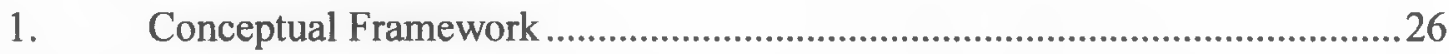

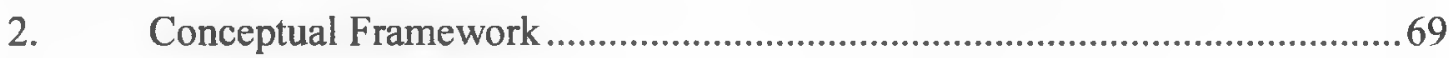

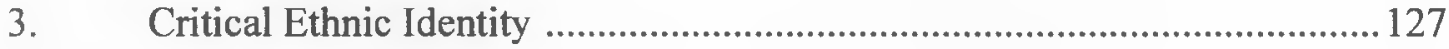




\section{LIST OF APPENDICES}

Appendix

Page

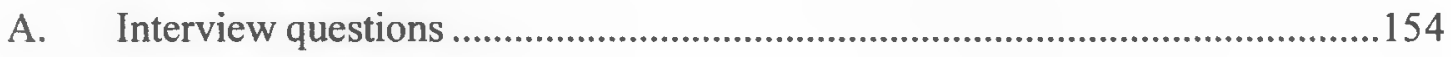




\section{Chapter One: Purpose of the Study}

I'm also proud of my culture, of where I'm from because a lot of people here aren 't maintaining where they're from, where their blood is from (Jasmine, high school student).

They are developing an identity and we are here to just support them (Griselda, dance teacher).

Years ago, the community coordinator at the middle school where I was principal invited me to attend a Oaxacan festival she had organized in the center of our city. I had helped translate the program from Spanish to English and from this understood that there would be a presentation of different dances. I dropped by with my husband on a Sunday afternoon expecting something small. What I found instead was a sold out event that had spilled out onto the streets. As an invited guest, I was escorted past families waiting for entrance, some of whom said they had made the journey from Los Angeles.

Inside the auditorium, the festival began with a parade of dancers and Monos de Calendas or giant puppets followed by a dedication in Zapotec, Spanish and English. The festival featured dances from the different regions of Oaxaca performed by dancers from groups around the Bay Area and students from our middle school who practiced each week under the direction of the same community coordinator. While there were many wonderful performances that afternoon, the performance of those students was the most remarkable to me. On stage, in front of more than 500 people, these students performed in traditional clothing with a confidence uncommon to the adolescents I knew. As the 
performance spilled out in to the street, students danced with parents and grandparents. Girls held the edges of wide and colorful skirts as they twirled around boys with hands clasped behind their backs tapping out a fast rhythm in black, shiny shoes. While I was watching, Guadalupe's mother pulled me in to dance to the live band that had followed performers outside. For this and other reasons, I left the event later than planned with a very different perspective and many questions.

As principal, I had known that there was a dance group practicing after school, but I had no idea what this practice entailed. I had translated the program, but didn't get the connection to indigenous culture. And most of all, I had no understanding of the depth of commitment on the part of parents, students and teachers to connect to their culture through music and dance. Just as my perspective was altered, I had many questions, most stemming from the difference between how students presented through this performance and in classrooms at school.

My questions specifically stemmed from a professional interest in the academic performance of our Latino/a students. In the quest to raise test scores, our district was looking at strategies to engage Latino/a students, to increase their participation in class and their proficiency on state tests. These proposed strategies came from observations that Latino/a students were often quiet in class and struggled with tests. After this performance I wondered, how then, could the same students who rarely spoke up in school perform with confidence in front of a crowd? How could students who struggle academically perform elaborate choreography that appeared to require tremendous focus 
and skill? All of our efforts to get students to speak up through Constructive Conversations and pre -teaching vocabulary (Kinsella, 2014; Olsen, 2011) weren't getting us anywhere, as evidenced by the same metrics we used to diagnose the problem. The performance left me wondering what we as school administrators might learn from students participating in cultural activity.

This study is a follow up to that Sunday afternoon where my perspective was challenged and I began to question how schools welcome and support Latino/a students. As I met with students and teachers, I learned that the dance group is a place for students to maintain their culture (Jasmine) and develop their identity (Chanel), and for these two elements to reinforce each other and provide a sense of home and rootedness. It is a place where students and their families create their own narrative of power and strength in contrast to the narrative held by many schools and educators that casts Latino/a students as "at risk". At school, many of our Latino/a students are enrolled in introductory math classes or "sheltered" science. These classes separate them from the White and Asian students who are enrolled in the regular or advanced track of study in secondary schools.

In contrast, within the dance group, there is no "slow" group nor is anyone considered below standard. All students are required to attend the same practice and execute the same choreography. All students interact with caring adults who know their story and challenge them to do their best. And all students can participate in their first language. 
Placing Latino/a students in remedial or slow-paced classes has an impact on the assumptions and beliefs of their peers and teachers. Most notably, the positioning of Latino/a students as needing more support has led to some troubling teacher behaviors. The pobrecito syndrome (Noguera, 2008) captures the tendency of teachers to lower their expectations for Students of Color out of a sense of sympathy. Pobrecito translates to "poor little boy" and is an expression you hear most often when Spanish-speaking parents are chiding a child who is complaining about something small, literally spilled milk, for example. Noguera (2008) used this expression in his book The Trouble With Black Boys ... and Other Reflections on Race, Equity, and the Future of Public Education, as he discussed the ways in which public education contributes to widening the gap between White students and Students of Color as well-meaning teachers water down curriculum and lower expectations.

In my district, we see a disproportionate number of Latino/a students assigned to remedial courses and their underrepresentation in AP classes. We have reviewed the feedback teachers provide on essays and how often Latino/a students are called on in class. Administrators conducting walk-throughs have noted that often Latino/a students can sit quietly in class without being required to respond. From their class schedules to interactions with teachers, it seems as though we expect less of Latino/a students and this lowered expectation contributes to the ever-widening achievement gap.

By contrast, there are no "pobrecitos" in the dance group, only students who may need an extra push. There is consideration for individual differences, but not lowered 
expectations. And the result of this approach was clearly demonstrated through the performance I witnessed that Sunday afternoon. Through public performances, the dancers create their own communal narrative that acts to counter deficit lenses applied by schools. Through community solidarity via performance, they demonstrate the wealth of their culture for themselves, their families, and the larger community.

This dissertation brings together observations about the dance group in response to the larger question of how schools can better support the social, cultural, and academic achievement of their Latino/a students. What might we learn from these students' experiences in a cultural dance group that would lead to restructuring a more communityand strength-based approach to students whose languages and cultures are not fully represented in schools? And what policy and leadership implications does this have for educational leaders, like me, who are committed to closing the achievement gap for students?

Studies on inequitable outcomes report that Students of Color often attend schools where their teachers use constructs that privilege Whiteness (Gay, 2010; Sleeter, 2008). From history texts to teacher ethnicity and language use, White students' identity and culture are affirmed while Latino/a culture is confined to limited references to specific individuals and events.

Latino/a students make up the majority in California schools and chances are good that they will spend most of their time in school instructed by a White teacher using curriculum that references White culture. Students in $9^{\text {th }}$ grade English classes in my 
district read To Kill a Mockingbird, Huckleberry Finn and Romeo and Juliet. Some teachers include Rudolfo Anaya's Bless Me Ultima and maybe Sandra Cisneros' The House on Mango Street, a book that many of us would have to replenish each year for all the copies students "borrowed".

Their U.S. History class will devote a few pages in the unit on Manifest Destiny to the General De Santa Anna's sale of Mexico to President Jackson and the Bracero movement where Mexican men were brought to the United States to provide labor during WWII. In addition to the paucity of references to Latino/a culture and history, fewer than $5 \%$ of our teachers are Latino/a. For all the Latino/a students who sit in our classrooms, there are too few examples of their culture in their teachers and in their textbooks.

In California, fewer Latino/a students complete high school and participate in Advanced Placement classes than White students (Radford, Berkner, Wheeless, \& Shepherd, 2010). Across California, performance on the state tests in 2015 showed a gap by more than 30 percentage points between White and Latino/a/Hispanic students who scored proficient on both math and English Language Arts. For Latino/a students and their families this data illustrates an achievement gap with dire consequences. Students who score below proficient in $4^{\text {th }}$ grade are twice as likely to be behind by $8^{\text {th }}$ grade and to not graduate on time. Failure to graduate and go on to earn a degree has serious consequences on their earning power. A college graduate earns on average twice that of a worker with a high school education. Setting aside the other benefits of a college 
education, the economic consequences of the achievement gap alone indicate how the cycle of poverty is maintained.

The data illustrating this gap prompts educators to propose interventions and support. Our district has set a goal to close the achievement gap for Latino/a students, and we monitor Latino/a students' performance calculating average daily attendance, grade point average, and the likelihood of graduating on time and their proficiency on standards. Well-intentioned teachers guide students through a maze of math support, binder organization, five-paragraph essays, and academic vocabulary so that they may access a better life than that of their parents. Latino/a students are assigned to special "intervention" classes during and after school designed to make up for the deficits in their education that are seen as responsible for their low test scores.

Rather than study the impact of these interventions, I chose to study a Mexican folkloric dance group that meets outside of school at an alternative high school campus. On Friday nights and Saturday mornings, members of the dance community fill every inch of the main floor at Midtown Alternative High School. While students practice in the auditorium, their parents spill out into the hallways working on costumes or headdresses. Younger children have their own dance practice in the foyer and the parent board meets in a classroom down the hall.

Within the dance environment, Latino/a students respond to each other and their teachers with confidence and self-assurance. Toward the adults, they are playful and serious, a reflection of the strong relationships within this community. The focus and 
engagement students demonstrate during dance practice is not always replicated in their classes at school. In fact, during my interviews, students often reflected on the rigor required at dance practice not expected at school. In dance practice, everyone is included and expected to learn the choreography. In schools, dancers and dance teachers pointed out, there is "tracking" with more Latino/a students ending up in basic or remedial classes while White students take the advanced classes.

Another aspect of the dance group is the relationship between participants, both younger and older. Students are at the center of conversations and all meetings are focused on their wellbeing. Parents, teachers and other members of the community are knowledgeable about each student's challenges including schoolwork, friend group or for the older students, their work environment and college classes. This community strategizes together to create solutions for problems our schools may not even know exist. For example, one of the dancers was found to be living on his own after his parents were deported. Members of the group found a place for him to live. Another dancer was assaulted as she crossed the border in search of her mother. The dance group provides a place where she is building positive relationships and trust after a harrowing experience.

Through the voices of students participating in a Mexican folkloric dance group, I hope to shift educators' perceptions of the role of cultural activity in preserving cultural identity, offering a strength-based view of Latino students, and supporting students' academic learning outcomes. Folkloric dance provides critical connections to culture, history and community missing for Latino/a students within our schools. This study 
explores the impact of these connections to better understand how educational leaders, working with teachers and families, can close the achievement gap.

\section{Statement of Purpose}

This study focused on the experiences of Latino/a students participating in a baile folklórico (Mexican folk dance) group and the impact of that involvement on developing an ethnic identity and critical consciousness through recognition of cultural capital. The arts can support engagement and achievement for Latino/a students in environments where their culture and language are not represented. This is especially critical in public school districts that have seen a significant decrease in access to the arts for students due to funding cuts and increased academic standards and assessments. Instructional leaders may look to ethnic arts as an activity that promotes engagement and achievement for linguistically and culturally diverse students. In this study, the Latino/a students participating in baile folklórico are highly engaged in the dance group and at school. Their experience in both environments provides insight into the impact of ethnic activity on achievement and engagement for educators and instructional leaders.

Baile folklórico is a term used for a collection of dances that originate in Mexican indigenous cultures and mestizo communities. These dances represent the culture, history and customs of the people of Mexico before and after colonization by Spain. Some dances retell a myth or historical event, while others highlight rituals and daily life. Distinct costumes, hairstyles, and choreography identify the regions from which the dances originate, representing the diverse cultures and economies of Mexican people 
(Nájera-Ramírez, 1989). As students learn each dance, they also gain knowledge about the plurality of cultures that pre-existed the arrival of Spain and that continue to exist within the 31 states of Mexico.

\section{Folkloric Dance in Mexico}

Folkloric dance has been influenced by the rise of social and political movements in both Mexico and the United States. With the arrival of the Spaniards in 1500's, the dances took on European influences. The increased contact within and across Mexico and Europe led to the inclusion of ballroom dances including the waltz and polka (Martinez, 2005). Folklórico reflects a complex relationship with Europeans. The Conquista depicts the conquest of the Aztec empire by Spain. Performance of this dance highlights the courage of Aztec warriors in a battle that ends in the death of their leader. As the conquerors became colonizers, dances developed that reflected European influence (Nájera-Ramírez, 1989). This was the beginning of the mestizo period as choreographers drew upon European influence to develop new dances that reflected a society in which Europeans created an upper class.

Following the Mexican Revolution (1910-1920), the Mexican government set out to develop a strong national identity. The revolution had divided the country between those who sought to maintain a connection to business and political interests with European and American companies and a desire for land reform to benefit the peasants. To unite Mexico in the years following the Revolution, the government drew on folk dance as a way to recognize diverse cultures and promote a national identity (Hellier- 
Tinoco, 2005;Nájera-Ramírez, 1989). In the 1930’s, fine arts centers throughout Mexico provided dance lessons.

The Mexican government's involvement in the arts had political and economic purposes. Within the 31 states, there are at 12.7 million indigenous people ( $13 \%$ of total population) with 62 different languages (Mexico-Indigenous People, 2016). Recognition of these diverse groups was an important step toward developing a national identity. The government created the Department of Cultural Missions whose purpose it was to collect dances and teach them to children in schools. The dances' authenticity was lost through this process, as the government's "cultural missionaries" did not have much training or experience. Removing the dances from their cultural context and adapting for school children had a negative impact on preserving the authenticity as well (Nájera-Ramírez, 1989). As a result, the promotion of indigenous cultures through dance was superficial at best. Like the multicultural movement in the United States in the 60's and 70's, the government of Mexico could be criticized for its token recognition of diversity for the sake of unification (Joseph, Rubenstein, \& Zolov, 1940).

When interest declined in the 50's and 60's, the government sponsored Ballet Folklórico de Mexico founded by choreographer, Amalia Hernandez. This group performed across Mexico and internationally with the dual goals of preserving Mexican culture and attracting tourists (Nájera-Ramírez, 1989). 


\section{Folkloric Dance in the United States}

In contrast, the interest in Mexican folkloric dance in the United States grew out of a social movement and in response to discriminatory practices against Mexican Americans. Prior to the 1960's, folk dance was taught in schools as part of the general education. In California, the standards for first grade physical education continue to include La Raspa, or the Mexican Hat dance, as part of the aesthetic valuing of different forms of dance. While dance was part of the curriculum within schools, folk dance in particular continued to be shared within Mexican American communities outside of school (Feay-Shaw, 2002;Nájera-Ramírez, 1989).

There was a resurgence of interest in folkloric dance in the 1960's as part of the Chicano Movement (Nájera-Ramírez, 1989). Folk dance performances supported and affirmed the identities of Mexican American people living in a society dominated by White culture and language. During World War II, Mexican Americans served in the U.S. armed forces and the Bracero movement brought in contract laborers from Mexico to work in American fields. At the conclusion of the war, discrimination and violence against Mexican nationals and Mexican Americans spiked. Those laborers who served the United States during the war were summarily deported back to Mexico as American soldiers returned from the war to job shortages (Operation Wetback). In addition to deporting Mexican nationals, some American citizens of Mexican heritage were also sent to Mexico in error (Rumbaut, 1994). 
The Chicano Movement sought to address this discrimination through developing a greater sense of ethnic identity and solidarity within a culture where Mexican Americans were marginalized. El Movimiento was a sociopolitical movement to promote and affirm the identity of Mexican Americans through visual and performing arts that replicated the indigenous cultures of Mexico. The arts movement connected also with organizations such as the National Farm Workers' Association who used el aguila negra (the black eagle) as their symbol. The black eagle was reported to have brought the original inhabitants to Tenochtitlán (Mexico City). By using indigenous symbols in art, the Chicano movement connected Mexican Americans to their culture of origin at a time when they were denied full participation in the American economy, educational system and society (Gustafson, 2004).

The influence of El Movimiento on promoting Mexican arts could also be found within the Chicano student groups at universities. These groups performed baile folklórico as a recruitment tool to illustrate that higher education was a possibility for Chicano students. Although baile folklórico received support from the Chicano movement, it held a different role than other art forms that were also at the forefront of $E l$ Movimiento. While theater, music, and visual arts took on the themes of social justice, performances of baile folklorico did not reflect the changing context of the lives of Chicano people.

The producers of murals, theater works, and music were all inspired by the Chicano movement to express Mexicanidad (the quality of being Mexican) as well as to 
use their art form to contextualize the experience of Chicano people within an environment of racism and oppression. Luis Valdez, the artistic director for Teatro Campesino, wrote and produced short "actos" (plays) depicting the plight of farm workers that were performed in union halls in 1965 . Fueled by the Chicano movement, El Teatro continues to use theatrical performance to call out injustice and express the culture of Mexican Americans. They were and are committed to engaging social change through the arts.

The rallies where Teatro Campesino performed also featured folklórico groups like Los Lupenos of San Jose. Participation in this folklórico group provided Russell Rodriguez with connection to his culture and the opportunity to perform. Reflecting on his experience with Los Lupenos in the early 60 's and 70 's, Rodriguez (2009) shared that through performances at rallies he was exposed to artists engaged in social commentary on injustice for Latino/a people. Offstage waiting to perform, Rodriguez saw theater groups depict the struggles of farm workers and the valiant efforts of Cesar Chavez. In contrast, the folkloric dances he performed provided a connection to the past, but didn't acknowledge the present experiences of Latino/a people living in a racist environment. As his eyes were opened to the possibilities for art to reflect lived experience, Rodriguez moved on to learn Mariachi, and discovered that the interactions between audience and performers recontextualizes what is means to be Mexican and living in the United States. Rodriguez' essay illustrates a critical difference between folklórico and other art forms that were influenced by El Movimiento. 
Mexican folkloric dance continues to maintain a strong presence within the Latino/a and Chicano communities as well as in the broader national context. The group Baila Baila performed as representatives of the United States at the 2012 Olympics and the group Ballet Folklórico Huehuecoyotl from Pueblo Colorado has performed for President Obama at the White House (Martinez, T.V.). Across the United States, performances by folkloric dance groups provide an intersection between the cultures of Latino/a communities and the more dominant cultures maintained within schools.

\section{Problem Statement}

This study is influenced by statistics that highlight a failure on the part of our K12 school system to support engagement and academic performance for all students. As the number of Latino/a students increases, there is a gap between the percentage who graduate from high school and go on to attend four year college as compared to White and Asian students (Darling-Hammond, 2010; McKinsey \& Company, 2009).

In California, where $53.2 \%$ of students are Latino/a (California Department of Education, 2013a), the percentage of Latino/a students who did not finish high school was almost twice that of White students (California Department of Education, 2013b). Furthermore, Latino/a students are underrepresented in the percentage of students completing the A-G requirements for entry to a four-year university (59\% White and $18 \%$ Latino/a). For Latino/a students who do graduate, $55 \%$ of those who enroll in college will not finish their degree (Radford, Berkner, Wheeless, \& Shepherd, 2010). 
The data illustrate the inequitable outcomes for Latino/a students and an analysis of structures and practices within the K-12 system addresses the cause. The achievement gap for students can be attributed to a curriculum, teaching force, and instructional model that do not represent the culture of Latino/a students. While Latino/a students represent the majority of students enrolled in K-12 education in California, they attend schools where the teaching population, curriculum choices, and instructional methods reflect White culture and contributions.

Lucas and Villegas (2013) argue that a teacher's orientation towards students whose languages and cultures are different from their own has a tremendous impact on classroom culture. In California, $81.9 \%$ of teachers are White, while the majority of students are Latino/a (NCES, 2010). In a study of White teachers working with diverse students, Ladson-Billings (1995) found that new teachers often resorted to traditional modes of teaching, failing to implement the culturally responsive strategies they had learned in their teacher education programs. Without ongoing training and support to shift their focus, teachers may revert to the default value of reinforcing the language and culture of the dominant group (Yosso, 2005).

Yoon (2008) compared Latino/a student participation in classrooms where teachers included their culture and language with classrooms where the teacher referenced only "American" culture. She found that the Latino/a students participated very differently in the two environments. In classrooms where the teacher acknowledged their culture/language, these students fully participated. The same students were quiet 
and non-responsive in the classroom of the teacher who referred to American football and pop culture.

Just as we look at factors contributing to the achievement gap, there are also recommendations for how we can narrow the gap. Studies of Latino/a student persistence include interviews with students who have found a connection to their culture and a sense of community within their college or university. These students joined groups that provided them with both a connection to their culture and support within their new environment (Perez Huber \& Cueva, 2012). Participants in these studies share stories of how this opportunity to connect with their culture and community provided a place of refuge and comfort within an environment where they felt excluded. Activities and clubs played an important role in the persistence of these students as they worked to earn a college degree.

\section{Research Questions and Proposition}

The research questions this study will address are: What is the experience of Latino/a students participating in a Mexican folk dance group? How does this experience support recognition of their cultural capital? How do participants make sense of their experiences within the dance group and at school? Building on prior studies of student persistence, the proposition for this study is that participation in a cultural activity leads to the development of an ethnic identity and critical consciousness for Latino/a students. Identity and critical consciousness allow students to better recognize and navigate through systems where they and their culture have been underrepresented. Given data 
that illustrate an academic achievement gap, educators have a mandate to review existing systems and strategies as well as the possibilities within cultural activity to better support Latino/a students with access to college and career.

This is a qualitative study with data gathered from observations of the dance rehearsals and from semi-structured interviews and focus groups with students and members of their families. The main participants were a group of 16 middle school, high school, and college students who have performed for at least two years with a Mexican folk dance group that holds their rehearsals in a school district building

\section{Significance of the Study}

Studies of the achievement gap have focused on the role of the K-12 education system on supporting students of color with access to college or career through adapting the instructional model or curriculum within school. This study prompts educators to look at the ways in which cultural activity, particularly in ethnic groups can help students of color develop a critical consciousness that may support their persistence within and beyond secondary school.

\section{Theoretical Framework}

Community Cultural Wealth (Yosso, 2005) provides the framework for the data collection in this study and the theory of Critical Consciousness (Freire, 1970) informs the findings. Community Cultural Wealth supports a perspective on closing the gap for Latino/a students through promoting recognition of strengths within their community. 
The theory of Critical Consciousness illustrates how recognition of those strengths can also emerge through a deeper understanding of race and racism.

\section{Community Cultural Wealth}

Community Cultural Wealth $(\mathrm{CCW})$ is the cultural capital of communities of color (Yosso, 2005). CCW developed in response to Bourdieu's theory of cultural capital that presumes social, cultural and economic capital is only gained through formal schooling or from family connections (Bourdieu, 1977). Bourdieu's theory explains how inequity is socially reproduced within systems controlled by those in power and that privilege the White and middle class. While Bourdieu's theory explains how inequity is maintained by those with family connections and schooling, the theory of Community Cultural Wealth illustrates the capital created in response to that inequity. $\mathrm{CCW}$ highlights the diverse knowledge, skills and abilities of communities of color accumulated through their experiences, relationships and exposure to racism. The six forms of community cultural wealth include:

1. Aspirational capital: The ability to maintain hopes or dreams even in the face of real or perceived barriers

2. Linguistic capital: Multiple languages and communication skills participants hold that reflect their family and community involvement

3. Familial capital: The cultural knowledge attained and sustained through kinship with extended family and community 
4. Social capital: Connection to community resources and networks that support navigation through institutions

5. Navigational capital: Skills and strategies for navigating through institutions that were not created with Communities of Color at the center.

6. Resistant capital: Knowledge and skills acquired through oppositional actions that challenge inequality (Yosso, 2005)

Community Cultural Wealth grew out of Critical Race Theory (CRT) that challenged deficit discourse that blames people of color for inequitable outcomes (Moll, 1992). Educators who engage in this discourse describe what students and their families are lacking in order to explain why students of color are not achieving. Comments about inadequate home support blame the family and home culture rather than place responsibility on the school system to support all students (Yoon, 2008). CRT shifts our focus away from deficit theorizing to the experience and knowledge of communities of color.

Critical Race theorists examine society and social structures through the lens of race and racism in a society where Whiteness is placed at the center. Community Cultural Wealth extends the work of Critical Race theorists by centering on the experience of people who discover sources of strength and knowledge within their community. Experience with affirmation and racism increase their understanding of cultural wealth. 
Several studies illustrate how underrepresented students find their community capital within environments where they are marginalized. In a qualitative study of undocumented college students, participants shared stories of their families' journeys that helped develop a sense of strength within their community. Shared stories of struggle and survival within cultural groups contributed to greater persistence as students negotiated within school systems that failed to acknowledge their culture and language (Perez-Huber, 2012).

Immigrant high school students found that their connection to primary language was a source of strength as they built relationship with each other and with community organizations. When school counselors failed to help them with college entrance exams, these students sought support through their families, friends and community organizations (Lou \& Antrop-Gonzalez, 2012). Both studies depict educational environments that failed to recognize or support students' cultural strengths and the community support that filled this gap.

Schools can foster the recognition of Cultural Wealth through structures that promote a connection to community (Jayakumar \& Allen, 2013). African American students participating in the Young Black Scholars program in their university learned about the strengths and knowledge of their community through mentorships. This university program provided students with access to role models who shared their journey within environments where their culture was not recognized. 
Community Cultural Wealth may also be supported through performance that promotes the voices of those who have been marginalized. Using theater as social activism, the group Culture Clash wrote and performed a piece that illustrated a struggle between Mexican immigrants and city officials in the 1950's over housing rights (Yosso \& Garcia, 2007). To develop the script for this performance, members of the group conducted extensive interviews with Mexican people who were evicted from their houses. Through performance, actors presented the perspective of marginalized people and the various forms of cultural capital that sustained their community in the face of oppression.

The connection between performance and Community Cultural Wealth is important to this study of folkloric dance. Dancers realize their strengths through performance even as they are exposed to bias and assumptions from those outside the community. Often rehearsal provides affirmation, while performance may expose dancers to ridicule. The dancers in this study shared that some of their peers, Latino/a and White, would make fun of the outfits and choreography. Yet, the dancers felt strongly that through performance, they were representing the strengths of their culture. One dancer stated, "I want people to know that Mexicans are not all bad like Donald Trump says," indicating that performance of folklórico could correct misunderstandings about her culture and community.

Demonstrating the strengths of Mexican culture and people is central to many folkloric dances. La Conquesa, or Los Marqueses, tells the story of the Spanish conquest 
of the Aztec Empire and depicts the strength and courage of the Aztec warriors. Moros $y$ Cristianos illustrates the battle between followers of indigenous religions and Christianity. Through these dances, performers and audience develop a stronger understanding of the racialized struggle between indigenous people and the European Colonizers that continues to present.

\section{Critical Consciousness}

While Community Cultural Wealth supports students' understanding of their strengths, Critical Consciousness may lead to an awareness of why those strengths are not recognized within a racist environment. Critical Consciousness or Conscientization develops when people understand injustice or inequity, their place within that inequity, and can take action (Freire, 1970). This consciousness can be developed through a problem posing process with a facilitator who encourages reflection on experience, building connection, and considering how to respond to racism. For young people, it is thought that Critical Consciousness supports their identity as a change agent and may lead to greater civic engagement (Diemer \& Lis, 2011).

The theory of Critical Consciousness is at the heart of studies illustrating how communities of color can affect change through dialogue with and about oppression. High school students who participated in a transformative initiative designed to increase their empowerment, engaged in critical conversations about educational equity (HipolitoDelgado \& Zion, 2015). The Critical Civic Inquiry project was designed to promote Critical Consciousness in marginalized youth and then measure the impact on their sense 
of empowerment. For this study, empowerment meant an increase in the sense of personal and interpersonal power leading to taking action to improve a situation for that individual or their community. Through a partnership between university and high schools a group of teachers were trained to deliver content through an approach that supported student understanding of educational inequity. Students in each course explored the source of the inequity and proposed solutions. This quasi-experimental study found that students who engaged in dialogue about inequity reported greater gains in their ethnic identity and sense of self-efficacy than those who did not.

The participants in this study on folkloric dance are underrepresented students who regularly perform their identity at events within school and the community. Their performances could be considered a dialogue between dancer and audience. In performance, the dancer shares their cultural identity and the audience responds. The dialogue continues outside of performance. A high school dancer shared that within the Latino/a community they were labeled as "those Mexicans who like to dance and wear those big outfits" in contrast to Mexicans who try to assimilate. Another student reflected that participation in dance puts "targets on our backs" as he was subjected to teasing and bullying at school. He shared a few examples that included mild teasing from close friends to being told he was "gay" and "retarded" by students he didn't know.

The participants in this study engage in an activity that both affirms their ethnic identity and exposes them to racism. Their responses to these acts show a connection to the development of a critical consciousness. They are aware of inequity and their 
connection to inequity. For some, dancing is a form of counter-story or response to that inequity, communicating pride in their culture through dance.

Literature in chapter two draws upon the theoretical frameworks of Community Cultural Wealth and Critical Consciousness to illustrate best practices within schools and community groups to support students whose language and culture is not at the center.

The best practices are defined both through participant voice and through an analysis of the measurable outcomes.

\section{Conceptual Framework}

The framework begins with Latino/a student participation in a Baile Folklórico group and examines how they make sense of this experience through the six forms of capital defined as Community Cultural Wealth (Yosso, 2005). Student understanding of their community wealth is then analyzed through the theory of Critical Consciousness (Freire, 1970) to determine the relationship between recognition of cultural wealth, ethnic identity and consciousness of racism within their environment. The final step in this framework examines the impact of critical consciousness on supporting achievement and persistence within secondary school and beyond. 


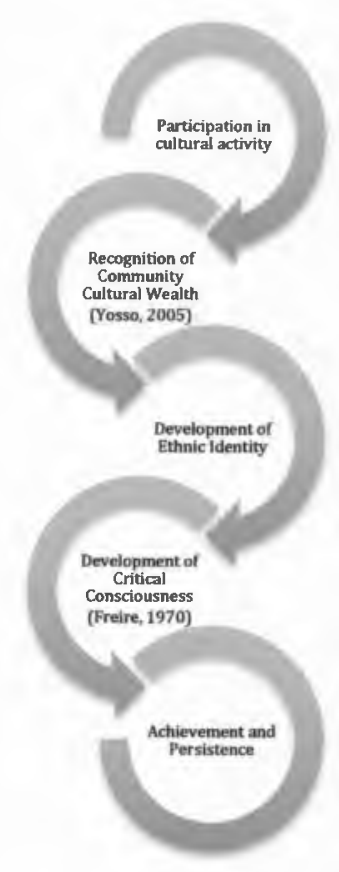

Figure 1. Conceptual Framework

\section{Summary}

This study shares the voices of participants within the theoretical frameworks of Community Cultural Wealth and Critical Consciousness to make recommendations for how school systems might better support Latino/a students. Chapter two will present extant literature on ethnic identity, critical consciousness and student outcomes. Chapter three provides the methodology for this study, along with the role of the researcher and expected findings. Chapter four will explore the findings and Chapter five offers implications of those findings for educators 


\section{Chapter Two: Literature Review}

Students who participate in cultural activity develop their ethnic identity, recognize cultural capital and confront racism within structures that privilege Whiteness (Perez-Huber, 2012). This study focuses on folkloric dance as cultural activity, although there are many other activities including art, cooking, celebrations and funerals that connect people with their culture. In this chapter I bring together literature to create a conceptual frame for an exploratory study of Latino/a students participating in a Mexican folk dance group. The literature examines how cultural activity within and outside schools can promote students' understanding of their cultural capital, and the impact of that understanding on supporting ethnic identity, critical consciousness, academic achievement and persistence.

\section{Methodology}

This review includes literature on the development of student ethnic identity, Cultural Wealth, critical consciousness and the impact of that knowledge on their outcomes. I used ProQuest, Google Scholar and EBSCO to locate extant literature that was both exploratory and explanatory. Additionally, I searched for recent dissertations (unpublished papers) of researcher/practitioners who were examining the practices at their school or district.

I used the key words persistence, post secondary, Latino/a students and baile folklórico to locate studies that would provide outcome data for students involved in this 
form of dance. I also searched for literature on the impact of Ethnic Studies in Tucson as well as a review of research on Ethnic Studies throughout the United States.

The literature I reviewed examines how schools and outside activity can promote ethnic identity development and how that identity leads to supporting Latino/a students within structures that privilege Whiteness. While many studies have examined the impact of these practices on identity development, there is scant literature focused on the role of cultural activity on increased academic achievement and engagement through critical consciousness.

\section{Structure of the Review}

This literature review begins with an overview of the political and social movements influencing research on educational programs that maintain a connection to home language and culture. The legislation and social commentary stemming from America's involvement in war and then in a fight for Civil Rights continues to be relevant to this study. The anti-immigrant sentiments expressed post-WWII continue to be part of national and international conversations in 2016.

The second section focuses on studies of the impact of maintaining home language and culture on ethnic identity development and the third section includes studies that illustrate how ethnic identity leads to increased outcomes for Latino/a students within structures that privilege Whiteness. These studies share the voices of students who recognize that their culture and language are not represented in curriculum. Through 
their voices, we learn about the potential for cultural activities to develop ethnic identity, and provide students with a critical lens and tools to respond to inequity.

\section{0 's to 1980 's}

Research about closing the achievement gap often references the period directly following the Civil Rights movement. From the 1960s-1980s, educational policies reflected the fight for recognition and rights of communities of color. Civil Rights activists promoted the inclusion of African American history within schools. This led to the beginnings of Ethnic Studies at universities that focused on a more inclusive curriculum for communities of color.

Educational policies were also influenced by an influx of immigrants to the United States following World War II as well as legislation coming out of the Civil Rights Movement of the 1960s (Ovando, 2003). Schools in the 60's were not prepared to or even invested in how to address the different language or cultures of students whose families were fleeing civil war or seeking economic opportunity. The sink or swim approach to assimilating non-English speaking students was called in to question as schools struggled to support linguistically and culturally diverse students. Success within dual immersion programs (education in the home language and English) for the children of Cuban refugees influenced several federal policies that directed schools to provide primary or home language support for students learning English as an additional language. 
The Bilingual Education Act (1968) required schools to both aid and monitor language minority students by providing access to instruction in English and their home language. This led to the creation of more dual immersion and bilingual education programs throughout the country designed to support biliteracy through instruction in home language. Research on this model illustrated that through maintaining a connection to primary language, students attain higher levels of academic proficiency and engagement (Cummins, 1991).

Unfortunately, this act did not widely influence practices in all parts of the country. In 1974, a class action suit was filed on behalf of Chinese students in San Francisco, claiming that failure to provide students with instruction in their first language was an act of discrimination (Baker \& Jones, 1998; Hakuta, 1986; Ovando \& Collier, 1998). In the case of Lau vs. Nichols, the courts determined that bilingual education was necessary to ensure that access to the curriculum for all language minority students.

Chief Justice Douglas spoke for the courts when he stated;

There is no equality of treatment merely by providing students with the same facilities, textbooks, teachers and curriculum; for students who do not understand English are effectively foreclosed from any meaningful education (Sugarman, S. D., \& Widess, E. G. (1974).

In 1974, the Equal Educational Opportunities Act expanded the influence of the Lau decision to include all schools, not just those receiving federal funding; 
No state shall deny equal educational opportunity to an individual on account of his or her race, color, sex or national origin, by... the failure of an educational agency to take appropriate action to overcome language barriers that impeded equal participation by its students in its instructional programs ( 20 U.S.C. 1703).

These policies created guidelines for bilingual programs that would ensure access for students learning English as another language.

The Civil Rights Movement also opened the door to the creation of an interdisciplinary field that put issues of race and racism at the center of curriculum. In 1969, the coalition for Ethnic Studies at San Francisco State University and UC Berkeley demanded inclusion of scholarship and curriculum from and about communities of color in K-12 and university environments. Unlike the bilingual movement, Ethnic Studies has at its core, explicit attention to the role of race and racism in privileging some forms of knowledge over others. The consistent themes within Ethnic Studies include:

1. Explicit identification of the point of view from which knowledge emanates, and the relationship between social location and perspective;

2. Examination of U.S. colonialism historically, as well as how relations of colonialism continue to play out;

3. Examination of the historical construction of race and institutional racism, how people navigate racism, and struggles for liberation; 
4. Probing meanings of collective or communal identities that people hold;

5. Studying one's community's creative and intellectual products, both historic and contemporary (Sleeter, 2007)

Ethnic Studies' programs affirm the knowledge of communities of color and deconstruct systems of inequity that keep White people at the center (Hu-Dehart, 1993). Research on Ethnic Studies found a relationship between racial/ethnic identity and academic engagement, achievement and personal empowerment. Qualitative and mixedmethods studies consistently demonstrated the correlation between curriculum that reflects students' culture and an increase in proficiency in reading, writing, social studies and math. In addition, students who participated in ethnic studies demonstrated a greater sense of empowerment and urgency around their educational goals (Sleeter, 2007).

\section{0s to Present: The Dismissive Period}

Within the past three decades, significant legislation has countered bilingual education and Ethnic Studies with policies designed to reduce access for students to their language and culture as part of the school day. With a downturn in the economy, a shift in political power and an increasing number of immigrants seeking a better life, legislation in the 1980's reversed several acts created post the Civil Rights Movement. Representing a shift in social and political opinion, President Ronald Reagan stated that bilingual education was wrong and didn't prepare students for the job market (Ovander, 2003). California seized on this sentiment and passed Proposition 227 making bilingual education illegal in public schools (Crawford, 1999). 
In 2011, the governor of Arizona eliminated an Ethnic Studies program citing the curriculum as divisive (Blankenship \& Lord, 2015). Tucson Unified School District had created the Mexican American Raza Studies program to engage their Latino/a students at a time of racial strife and conflict. The program gave Mexican American high school students the opportunity to learn about their culture and history as part of a regular course of study. Members of the Arizona Legislature passed HB 2281, which eliminated this program stating that the content was "too political" (Cabrera, Millem, Jacquette \& Marx, 2014). Although students participating in this program demonstrated greater proficiency on assessments, the governor cited the need for a unified curriculum. Governor Horne further asserted that the head of the Mexican American Raza Studies was teaching a "separatist, political agenda" (Horne, 2007).

The strength of bilingual and ethnic studies programs is supported by research that studies the connection between primary language and culture for underrepresented students with greater academic outcomes. Students who maintain a strong connection to their first language and home culture are more likely to engage in their studies and to perform at higher levels (Gay, 2012; Ladson-Billings, 1995). Proposition 227 and the demise of the Mexican American Raza Studies program indicate a larger, social mistrust of immigrants and diversity in education. Further, it is a reactive reform agenda that is not grounded in research, one that is likely to hurt Latino/a student achievement. This literature review will include several studies that were launched after the demise of programs that promoted bilingual education and ethnic identity 


\section{Cultural Activity and Ethnic Identity}

Inclusive curriculum, caring relationships, and a space to counteract hegemony all help students develop their ethnic identity and recognize their Community Cultural Wealth. Valenzuela (1999) calls on educators to recognize how through curriculum and pedagogy, teachers send explicit and implicit messages about their Latino/a students. She says, "Mexican youth continue to be subjected on a daily basis to subtle negative messages that undermine the worth of their unique culture and history" (p. 340). As students of color navigate systems dominated by Whiteness, there is little opportunity to connect with their ethnic identity.

Ethnic Identity

The studies reviewed in this section highlight structures and programs that demonstrate support for the ethnic identity development of underrepresented students. The concept of ethnic identity can be defined as an individual's self concept within their group and how that individual or their group is perceived by others (Tajfel, 1981). Other writers have included one's knowledge of their culture's language, behavior, history and values as part of an ethnic identity (Rogler, Cooney, \& Ortiz, 1980).

These components of ethnic identity are strongly supported through Mexican folkloric dance. Choreography and costumes communicate the history of the different cultural groups in Mexico. Language and values are shared through the narrative behind each dance, reflecting both the historical events as well as daily life. For example, in dances from the state of Jalisco, women wear "adelita" dresses of women who fought in 
the Mexican Revolution of 1910. In Danza del Venado, male dancers depict the hunt for deer conducted by the Yaqui people. Both dances illustrate how folklórico promotes an understanding of the history and values of the different regions of Mexico and promotes an ethnic identity for the dancers.

Ethnic identity is also influenced by how others view the individual or their group (Nagel, 1994). An individual from Mexico may identify as Oaxacano or Zapoteco. The first identity is connected to their state of origin whereas the second is related to membership within an indigenous group in that state. Outsiders may label this same individual as Latino/a, a term that is more general and does not accurately reflect their origins. The distinction between self-identity and perceived identity contributes to the complexity of one's ethnic identity.

This identity is an important factor in the study of students engaged in cultural dance. Folklórico provides membership in a cultural group that provides social and community solidarity across age groups and geographic boundaries, and provides a strength-based view of the students' social, cultural, linguistic, and artistic talents. Through dance performances, it increases interactions with outsiders, who often hold different perceptions of the dancers' cultures and identities. The participants' ethnic identity is comprised of their understanding of identity within the group as combined with the perception of outsiders. The studies in this section illustrate the ways in which schools can promote the ethnic identity of their students through cultural activity, including folkloric dance. 


\section{Folkloric Dance and Ethnic Identity}

Most of the literature on Mexican folkloric dance and Latino/a students in the United States references dance as a way to bring parents to school events or provide acknowledgement of Latino/a culture. Sheets' (1995) case study of Latino/a high school students enrolled in AP classes, mentioned the importance of Baile Folklórico for parent engagement. Similarly, Wallensteins' study of Latino/a elementary students living in poverty made note of how Baile performances would bring parents to school. Of the 35 articles that surfaced through a search of Baile Folklórico and education, only five explored the impact of dance on student ethnic identity. Several other studies grouped Baile Folklórico as part of the research on multiple intelligences. Those studies addressed the need for all students to have instruction that supports their learning through multiple modalities.

Along border towns between the United States and Mexico, schools have also introduced Mariachi instruction as a supplement to or replacement for band programs. Studies of the schools that included Mariachi found that more Latino/a students signed up for music classes (Ballard, 2002; Barba \& Soto, 2007). Most recently, the superintendent of San Francisco Unified School District, Richard Carranza, brought Mariachi instruction to students at Mission High School. As a social studies teacher in Tucson Arizona, some 20 years ago, Carranza had started a Mariachi program pointing out that 
It brought recognition of who they are (Latino/a students), their cultural heritage, into the school. We wanted to diversify what we considered art (San Francisco Chronicle, March 19, 2015).

On the school district's website, Carranza communicates a mission statement for including Mariachi that speaks to the importance of ethnic arts in supporting Latino/a students as he invites the public to the first annual Mariachi concert performed by students.

As a mariachi musician and former music teacher, I know how mariachi can also help bring recognition of students' cultural heritage into school. At SFUSD, we want to provide students with diverse and expansive offerings in arts education. (SFUSD web site)

The growth of Mariachi and baile folklórico in communities across the United States speaks to an increasing awareness of how participation in ethnic arts may provide more than entertainment. For students and their families, opportunities to learn ethnic arts provide a connection to their ethnic identity.

In a search of articles published in Mexico, I found an essay in La Tarea, Revista de Educacion y Cultura (Homework: Journal of Education and Culture), published by Nicholas Cruz Valle (2009) that encouraged educators to consider the role of folk dance as identity development.

Este género dancístico forma parte de las manifestaciones artísticas que el hombre ha expresado siempre desde sus orígenes. Su práctica puede facilitar el 
desarrollo de las personas como mejores seres humanos, pues no sólo es bailar por bailar, sino que se adquiere la capacidad de sentir, comunicarse físicamente, expresar emociones y sentimientos, definir su identidad nacional y actuar de manera libre y espontánea ante los demás, con quienes convive de manera cotidiana. [This dance form is one of the artistic manifestations that man has expressed since the beginning of time. Participation can facilitate our development into better human beings, but this is not only dancing for the sake of dancing. It is acquiring the capacity do feel, to communicate with your body, to express emotions and feelings, define your national identity and respond in a manner that is free and spontaneous with whoever you live on a daily basis.]

Valle's valuing of dance extends to the classroom with a reference to Vygotsky and mediation through symbols.

Sólo mediante el aprecio, goce y disfrute de nuestras raíces, podremos defender eficazmente nuestras costumbres y tradiciones. De acuerdo con Vygotski, pudimos recordar que la mente y el pensamiento operan mediante símbolos; que estos son mediadores de los planos interpsicológicos e intrapsicológicos que permiten internalizar la cultura, una cultura a la que todos estamos condicionados desde nuestro nacimiento y que, a la fecha, hemos de entenderla como sujetos que actuamos sobre los objetos que la conforman. [Only through the appreciation and enjoyment of our roots, we can effectively defend our customs and traditions 
According to Vygotsky, we could remember that the mind and thought operate by symbols; these are mediators of interpsychological and intra-psychological planes that allow internalizing the culture, a culture that we are all conditioned from birth and, to date, we have to understand as subjects who act on objects that form it.]

This article speaks to the role of folk dance in developing a national identity, preserving and defending customs and becoming a better human being. While Cruz Valle does not define what it means to be a better human, this essay clearly reflects the importance of dance beyond art.

The studies I found demonstrated the impact of cultural activity on ethnic identity through dance. However, only one study addressed the question of how that ethnic identity through arts impacts student outcomes. This1981 study examined the impact of ethnic dance on 60 students at Mission High School. Like Cruz Valle, the researcher thought that dance might be more than just an art form. Trujillo (1981) proposed that through exposure to curriculum about Latino/a culture and history through dance, students' self-concept and academic achievement would increase. The rationale for the study cited low academic achievement for "ethnics" and blamed mainstream curriculum as a factor in low self-concept and motivation for the "ethnically different".

Students in Dr. Trujillo's study were randomly selected to participate in a 6-week course on Mexican folkloric dance. They learned about indigenous cultures of Mexico 
through folkloric dances and mini lectures. Student self-concept was measured through the Tennessee Self-Concept scale prior to and after the course. In addition, the research team observed students in their regular classes and monitored their academic performance. Student self-concept and academic performance in their classroom increased for students in the treatment group. In addition, researchers noted that these students were more engaged in class with fewer behavior incidents. Trujillo recommended further study into the impact of ethnic dance on cognitive growth. This study used a quantitative design to make connections between the cultural activity and measurable outcomes. Trujillo's research questions were similar to those on which this study is based. My study extends this work to include student voice using ethnographic methods.

This recommendation to study cognitive growth connects with a study of six highperforming high schools (Lucas et al., 1990). The schools in this study were recognized for the strong academic performance of their majority Latino/a population. Staff at the high schools demonstrated respect for Latino/a students' language and culture as reflected in course offerings and after school activities. The administration and staff encouraged students to speak in their native language. Many teachers spoke Spanish and had visited Mexico to learn more about their students' culture of origin. Celebrations at these schools reflected a deeper understanding of significant events, beyond the standard Cinco de Mayo festivities, which provides only token recognition. Instead, this curriculum and set of course offerings supported students' ethnic identities. Further, the 
teachers brought in Latino/a culture through teaching folkloric dance in the physical education classes. Through lessons on folkloric dance, high school students learned about the history of different regions in Mexico. They also learned that their school placed high value on Latino/a culture and history (Lucas et al, 1990; Ostler, 2011 Soto, 2012).

Participation in folkloric dance can be both explicit and implicit curricula in ethnic identity formation. From interviews with Latino/a youth performing in a folkloric dance group McClain (2004) found that their participation helped form a positive identity. Rehearsals and performance provided participants with a connection to their culture all the while affirming that their culture has value. The costumes, steps and music all connect to regional history and events. The act of performing that history helped participants develop their ethnic identity. Through rehearsals and performance they honored their heritage and received accolades from members from of their cultural community as well as outsiders. This experience strengthened their connection to being Mexican American.

\section{Folkloric Dance, Ethnic Identity and Counterspace}

Cultural activity can provide a space in which participants can counter the dominant culture and better understand their ethnic identity. In a study of Latino/a students in post secondary education, their participation in baile folklórico created a "counter space" where they could be proud of their culture and heritage (Perez Huber \& Cueva, 2012). Students described this space as affirming their culture and identity within a larger environment of racism and oppression. Within a high school environment, 
Latino/a immigrant students described how they are "racialized" by the reactions of White students to their clothing, language and culture (Soto, 2012).

[Now] I feel more Mexican, yes, like, now that I see what discrimination is and here, I feel real proud to be Mexican because I see what all Mexicans do, all they do so their families can prosper, that makes me feel real proud to be Mexican. (Olivia, page 19)

The students expressed pride in their culture and believed that involvement in ethnic groups and activities allowed them to affirm their identity as Mexican American. One of these students who participated in Baile Folklórico performances at school said that dance stood out within the overwhelming Whiteness of culture.

While Baile provided such a space, there were other spaces created informally where students could speak in Spanish. These students had developed daily routines that ensured they could meet up and share their day. This space helped them to negotiate an often unfriendly, anti-immigrant culture within their school.

The need for space to assert identity and belonging can be illustrated in studies of immigrants who find other ways to promote their culture in public venues. Becerra (2014) noted that soccer games and Mexican Day parades in New York City served as temporal spaces in which Mexican Americans, (many of whom were undocumented), could enact their identities and membership within a community. The participants in these activities drew strength from the outward display or performance of their ethnic 
identity in neighborhoods where they had experienced discrimination. Fighting for a spot on the basketball court or applying for a permit to hold a parade are acts of both claiming recognition and affirming identity.

The studies in this section spoke to the importance of folkloric dance in developing an ethnic identity. However, the findings do not include how that identity leads to increased outcomes for underrepresented students. The following section extends the literature review to studies of the impact of this ethnic identity development on persistence, academic achievement, engagement, and critical consciousness. While these studies do not reference Mexican Folkloric dance, they illustrate the impact of ethnic identity on closing the opportunity gap for underrepresented students.

\section{Ethnic Identity Development and Student Learning Outcomes}

In this section, I review studies that illustrate the impact of ethnic identity development on post-secondary persistence, academic achievement and increased engagement in school. This section begins with a description of the problem through statistics that illustrate an opportunity gap for Latino/a students beyond the K-12 setting.

\section{Persistence and the Opportunity Gap}

Only $13 \%$ of Latino/as have completed an undergraduate degree as compared with $30.6 \%$ of non-Hispanic Whites (Cerezo \& Chang, 2012). These percentages represent the students who started and completed a program within a four-year university or college. The percentage of Latino/a students who start at a four-year institution and will earn their baccalaureate degree within six years (Berkner et al., 2012) is 47\% as 
compared with $67 \%$ of non-Hispanic Whites. These statistics point to a troubling trend. Even as the number of Latino/a students in post secondary institutions increases, the percentage that have access to and persist in higher education lags far behind their White peers.

Persistence and retention are often used interchangeably to reflect that some students continue their education while others drop out. The authors of studies focused on outcomes use persistence to refer to students in high school and community college who maintain strong attendance and participation. In selecting these studies to reflect persistence, I defined the term as the phenomenon of a student maintaining participation in a program, whether that program is situated within higher education or high school. Studies of persistence for students of color reference the theory of social integration as well as the concept of acculturative stress. In the following sections, I discuss both as they pertain to the literature on persistence for students of color.

\section{Social Integration}

Tinto's (1993) theory of social integration states that participation in the social life of a higher education institution is a predictor for persistence. This theory posits that if students fully participate in the college environment they will be more likely to continue their studies at the same institution. Tinto's theory was, however, criticized for not considering the application of this model for students from diverse backgrounds (Braxton, Sullivan, \& Johnson, 1997). Missing from this theory is the experience of underrepresented students for whom the dominant campus culture presents barriers to 
social participation. The earliest theories of student departure or drop out placed the problem on the shoulders of students who had failed to "integrate" into the campus culture.

Thus, Tinto's theory of persistence highlights the problem rather than the solution. The authors of studies in this section agree that participation and membership are essential factors in student persistence. Yet, they diverge from Tinto as they recommend that institutions of higher education do more to create a space for underrepresented students to connect with their home culture through activities or student groups.

\section{Acculturative Stress}

Central to the problem of persistence is acculturative stress that individuals experience when they find themselves in an environment different from their culture of origin. Acculturative stress can stem from exposure to or experience with cultural values, practices and language that differ from a student's home culture (Gil, Vega, \& Dimas, 1994). This stress leads to anxiety and depression as the individual feels pressure to assimilate into a new culture (Williams \& Berry, 1991).

Olga Nájera-Ramírez described her experience as a first generation Chicana at the University of California, Santa Cruz where she was surrounded by White culture. Her presence at the University was not supported nor encouraged by her high school counselor whom she describes as having a "paternalistic view of minorities." As a participant in an oral history project, Nájera-Ramírez shared her reflection on the 
counselor's intentions and the impact.

I think in his heart he thought he was being kind by telling us, "You guys should follow a vocational tech program, go to Cabrillo [College]. That's good enough for you. That's a good thing." So he played the same thing with me. And I'm like, "No, I don't want to be a secretary. It's a great profession for some people. I want to be a teacher." And he really didn't help me (Reti, I. H., Zepeda, S., \& NájeraRamírez, O., 2014).

Her own tenacity and support from her mother and siblings led to admission to the University where Olga found herself one of very few Chicana/o students. Her first year was characterized by a struggle to find her voice, surrounded by people whose culture and experience were different from her own, similar to her experiences in $\mathrm{K}-12$. Participation in ethnic music classes and the dance group Los Mejicas provided an environment on campus in which Mexican traditions and language were accepted and supported (Reti, et al., 2014). The studies in this literature review refer to acculturative stress as it manifests for Latino/a students in predominantly White universities or in school settings where their culture and language are not represented.

\section{Ethnic Identity and Persistence in Higher Education}

Students of Color are more likely to drop out of higher education due to factors within their experience and a negative university environment. Studies of persistence identified the structures and approaches that contribute to greater outcomes for students of color in post secondary settings. Peer support, membership in ethnic group 
organizations, and awareness of family strengths offset the microagressions students of color experience in predominantly White universities.

Wilson, (2012), found that involvement in ethnic groups and activities reduced "acculturative stress" for first generation students of color in college. Participants in this study discussed the impact of segregation in their classes and the support they received from membership in groups that promoted their culture and language. Wilson cites the work of Kuh and Love (2000), who make a direct correlation between the amount of time a student spends working within their culture of origin after high school and a reduction on cultural stress in a new environment.

In a similar study with racial/ethnic minority students, Museus (2008) found that participation in an ethnic group validated the experiences of the individual members. The participants in this study described their group as providing a place where they could express themselves freely and advocate for changes to the university setting. Students in both studies cited a university environment that was at times hostile to students of color. Through the ethnic group association, members addressed that hostility as a whole and advocated both for individuals and the group.

Hurtado and Carter (1997) examined the sense of belonging for Latino/a students and the factors that contribute to their success, with a focus on persistence. In this study, the researchers examined the antecedents in a students' experience prior to their first year of college. It is not surprising that students who had been involved in organizations prior to college continued their involvement that led to greater persistence. Additionally, the 
researchers found that mediation of course content outside of class provided a sense of belonging for students. This discussion was not connected to ethnic identity; however, Latino/a students shared that they found a sense of social and academic belonging through their participation in such groups.

A strong ethnic identity was also associated with a negative perception of a university environment (Castillo, 2006). A large-scale study focused on individual student identity and their evaluation of the school environment. They found that the greater a student's ethnic identity, the more likely they would have negative perceptions of the school. The negative perception of the university was also associated with attitudes of non-persistence. The researchers did not examine acculturation and assimilation amongst the participants, although they acknowledge these might have been significant to the findings.

By contrast, a smaller study of six Latino/a college students found that exposure to a negative environment supported a stronger connection to recognition of their Community Cultural Wealth that in turn led to stronger persistence (Delgado et al, 2012). This study captured the testimonios of Latino/a students between the ages of 18-20 who were at the beginning of their college experience. The narratives illustrated each student's experiences with oppression and racism, often within school environments. Through these experiences, students developed resistant, linguistic, and navigational capital that continued to be relevant to their experience at university.

Within their K-12 and university setting, students challenge inequity and 
misconceptions held by administrators about their families, their capabilities, and their goals. Several students described how their linguistic capital had given them multiple opportunities to interact with inequitable situations. As the language brokers in their family, these bilingual students often spoke up for siblings at school who needed additional support or, in one case, were inappropriately placed in a special education class. These experiences contributed to the students' sense of their own capital and desire to persist in higher education. Unlike Castillo's study, the participants showed signs of acculturation, although they maintained a connection to their culture of origin while navigating within the dominant culture.

Ethnic identity may be supported through group membership and through experience with racism. The authors of these studies affirm the importance of recognizing negative environments within universities for students of color. Their recommendations include providing students with opportunities to join an ethnic organization, discuss coursework, and reflect on their community wealth.

In the next section, I summarize studies on supporting persistence within high school. While there are many parallels between the recommendations for higher education and secondary school, distinctions can also be made based on the age of high school students and the structures inherent to secondary schools, which differ from those in higher education.

\section{Ethnic Identity and Persistence in High School}

The research on students who leave high school early names a number of factors 
within schools, the home environment and individual attributes. Within school, segregation, low expectations and inequitable educational programs are some of the factors that impact Latino/a students (Cammarota, 2006; Gandara, 2010). Studies in this section acknowledge the limitations within schools and highlight programs that challenge those limitations. These programs illustrate the impact of ethnic identity on persistence through increasing access for Latino/a high school students to community groups and caring relationships that affirm their language and culture

Three mixed methods studies examined high school programs in schools where there was an increase in the number of Latino/a students who were going on to college. In these studies, researchers found that students identified caring teachers and a program that included their culture as significant factors in their success. Lucas' 2012 study drew from the list of "highly effective" schools in California to explore the experiences of Latino/a students at the school. One of the criteria used to define "highly effective" was the number of students graduating on time. Using a combination of surveys, interviews, and review of student records, this study found eight features that contribute to the success of Latino/a students. Among those features were bilingual staff, an inclusive curriculum and strong relationships between students and teachers. While the schools did not offer specific programs, the orientation of staff and curriculum were directed toward creating an environment in which students' culture was recognized and supported.

Adults working within schools and community based programs can also serve as a "human bridge" (Stanton-Salazar, 2001), providing students with information about how 
to gain access to college. A study of programs within an urban high school illustrated the importance of adults who served to remove barriers to academic success and persistence through mentoring and tutoring students of color (Harris \& Kiyama, 2013). Interviews with students revealed the importance of these relationships as they navigated through course of study in high school and made plans for college.

A study of a migrant program found similar results with students who identified the importance of caring adults and activities that validate their culture (Gibson, 2002). This study used interviews, observations and student records to look at the impact of participation in the Migrant Education Program (MEP) as compared with Latino/a students who were not eligible for the program. The data reflected that MEP students had better outcomes than non-MEP students. Upon closer examination of the program, the authors found that through participation, students are guided to merge multiple worlds. Through building a network to both recognize and support Latino/a students, the MEP program and the schools in Lucas' study are successfully contributing to persistence.

\section{Ethnic Identity, Academic Achievement and Engagement}

This section begins with studies that demonstrate the relationship between curriculum that supports ethnic identity development and academic achievement/engagement. This is followed by studies of Ethnic Studies programs where students of color demonstrate high achievement and engagement. 


\section{Curriculum, Ethnic Identity and Engagement}

Curriculum that supports the racial and ethnic identity of students of color leads to an increase in academic achievement and engagement in school (Altsbul, Oyserman \& Bybie, 2008). These studies are particularly needed as the California adopted texts disproportionately mention White people over any other group (Sleeter, 2002). In secondary social studies texts, $79 \%$ of the people mentioned were White (Hughes, 2007). Studies to support ethnic identity should reference people of color and their contributions, but do so with an exploration of the role of race and racism. Ethnic Studies developed with a social justice lens and centers around three main concepts: Access, relevance and community. Access is defined as quality education for students of color, while relevance defines that education with a focus on the marginalized experiences of communities of color. The concept of community connects students and their studies to advocacy and activism with and for their community (Tintiangco-Cubales, 2012; Umaña-Taylor, A. J.,

Gonzales-Backen, M. A., \& Guimond, A. B. 2009).

Christine Sleeter conducted a review of research for the California Teachers' Association in which she examined published studies that document the impact of ethnic studies. The studies included elementary to high school settings within a range of content areas. While there has been a great deal of attention given to the Mexican American Studies program that started in 2008 in Tucson, Sleeter provides examples of curriculum 
going back several decades. One example is an elementary curriculum in Alaska that supports Yup'ik culture and study of math (Lipka \& Adams, 2004). Yup'ik students showed increased engagement and understanding through a model that replicated the cultural norms of collaboration with modules that centered on routines in their daily lives. The curriculum affirmed student ethnic identity and promoted cultural understanding through math problems.

Students of Color in university and high school disengage when their cultural group is not represented in the curriculum or when they see their cultural or ethnic group presented as victims (Mayheus, Grunwalk \& Day, 2005; Wiggan, 2007). In the review of research, Sleeter found three studies in which middle school students showed higher engagement with literature that was by authors from their ethnic background. In one study, $8^{\text {th }}$ grade students engaged in a semester long course that explored racism for African Americans as well as the traditions of West African people. Student engagement and connectedness increased through this course prompting the authors to recommend that Black History month be extended to a year (Lewis, Sullivan, \& Bybee 2006). This unit focused on empowerment through a dialogue about oppression. In contrast to studies that presented African Americans as victims, the unit illustrated the strengths through exploring resistance to oppression.

\section{Ethnic Studies Programs, Achievement and Engagement}

The Social Justice Education program in Tucson Unified School district followed the principles of a strong Ethnic Studies program. Latino/a students participated in a 
curriculum that was culturally and historically relevant and that challenged them to identify inequity within the past and present. This program developed into Mexican American Studies; a program that was eliminated by the state board of education due to claims of divisiveness. Latino/a students who participated in the Mexican American Studies program showed an increase in academic achievement and engagement over other Latino/a students as well as their Anglo peers (Cabrera, Miller, \& Max, 2012).

A report presented to Willis Hawley, the special master for the Tucson Unified School District Desegregation plan shared data on graduation rates and performance on state tests over four years. The data showed that three of the four cohorts of students were more likely to graduate than those who were not in the program. The students in the 2009 cohort were $51 \%$ more likely to graduate and those in 2008 cohort were $108 \%$ more likely. Over the four years, students in the Mexican American Studies program averaged a graduation rate of $95 \%$. White students in the same district averaged $84 \%$.

On the state tests, three of the four cohorts of students were more likely to pass all three sub-tests than their peers including White students. In addition, surveys of graduating students from the Mexican American Studies program showed in increase in the number of students who planned to go to college. The success of this and other programs can be traced to developing a strong ethnic and racial identity within curriculum that represents students' cultures and explores experiences with inequity and oppression. Critical Consciousness develops when people understand injustice or inequity, their place within that inequity and can take action (Freire, 1970). This 
literature demonstrates how the field of Ethnic Studies aligns with this theoretical framework by calling on educators to provide access to relevant curriculum that leads to connection with community and activism against social injustice.

\section{Summary}

The studies reviewed in this chapter demonstrated the connection between participation in folkloric dance and developing a strong ethnic identity. A separate group of studies illustrated how a strong ethnic identity supports academic achievement, engagement and persistence. There is a gap in the literature on the connection between participation in dance and greater student outcomes in school. This study extends the scholarship on dance and identity to examine dance, identity and outcomes through the lens of Community Cultural Wealth and Critical Consciousness. 


\section{Chapter 3: Methodology}

The research question calls for an exploration of the experience of Latino/a students participating in a baile folklórico group. Through this exploration I learned what the experience means to students whose language and culture is not well represented in the school setting. The methodological design for this study is qualitative, using ethnographic methods. Qualitative researchers are interested in understanding the meaning people have constructed, that is, how people make sense of their world and the experiences they have in the world (Merriam, 2009). The participants in this study were asked to make sense of their experience both in a baile group and within their secondary school or college. Through this study I explored what this participation meant to the students and what it could mean for educators. The design and methods allowed me to seek alternative perspectives on baile and potentially uncover counter examples to the narrative that promotes a deficit view of Latino/a students.

Ethnographic methods include a description of the group being studied, an analysis of this group in terms of their perspective and the researcher's interpretation of the group (Creswell, 2008). The first stage entailed observation, interviews, and agebased focus group made up of participants in the Baile group. The second stage consisted of an analysis of that data through descriptive coding. The analysis of these data led to the last stage: interpretation of data through the literature and describing implications and recommendations that are potentially applicable to a broader audience. 


\section{Population and Sample}

The participants in this study are 16 students between the ages of 13 and 22 who have participated in the same Baile Folklórico group for at least the past two years. The Baile group practices 2-3 days a week for a total of 11 hours each week. All of the participants are bilingual and many prefer to speak in Spanish. These students were chosen after multiple observations of dance practice over a period of four months. The students are consistently at practice and perform regularly in events around the city. I used purposive sampling to select participants who have a common experience in order to better understand the phenomenon of Baile practice and performance (Miles \& Huberman, 1994).

Table 1. Study Participants

*First generation refers to students who were born in Mexico and immigrated to the United States. Second generation students are U.S. born to one or more parents from another country.

\begin{tabular}{|l|l|l|l|l|}
\hline Student & Grade & $\begin{array}{l}\text { Years of } \\
\text { experience }\end{array}$ & $\begin{array}{l}\text { Generational } \\
\text { Status* }\end{array}$ & Aspiration \\
\hline Maria & $8^{\text {th }}$ & 4 years & $2^{\text {nd }}$ generation & Teacher \\
\hline Laura & $8^{\text {th }}$ & 4 years & $2^{\text {nd }}$ generation & Veterinarian \\
\hline Quetzal & $7^{\text {th }}$ & 5 years & $1^{\text {st }}$ generation & Attend UCSC or MIT \\
\hline Anahi & $7^{\text {th }}$ & 5 years & $2^{\text {nd }}$ generation & University \\
\hline Esperanza & $7^{\text {th }}$ & 4 years & $2^{\text {nd }}$ generation & Teacher \\
\hline Marisol & $7^{\text {th }}$ & 3 years & $2^{\text {nd }}$ generation & Nurse \\
\hline Flor & $11^{\text {th }}$ & 8 years & $2^{\text {nd }}$ generation & $\begin{array}{l}\text { International Affairs and } \\
\text { Linguistics in university }\end{array}$ \\
\hline Jasmine & $11^{\text {th }}$ & 6 years & $1^{\text {st }}$ generation & Pediatrician \\
\hline Carlos & $11^{\text {th }}$ & 5 years & $2^{\text {nd }}$ generation & $\begin{array}{l}\text { Mechanical or } \\
\text { environmental engineering }\end{array}$ \\
\hline Yesenia & $9^{\text {th }}$ & 3 years & $2^{\text {nd }}$ generation & College \\
\hline Belen & $11^{\text {th }}$ & 4 years & $2^{\text {nd }}$ generation & Midwife \\
\hline
\end{tabular}




\begin{tabular}{|l|l|l|l|l|}
\hline Luis & $10^{\text {th }}$ & 4 years & $2^{\text {nd }}$ generation & College \\
\hline Ana & Senior & 12 years & $2^{\text {nd }}$ generation & Math teacher \\
\hline Cecilia & $\begin{array}{l}\text { Community } \\
\text { College }\end{array}$ & 8 years & 1 st generation & University \\
\hline Maribel & $\begin{array}{l}\text { Community } \\
\text { College }\end{array}$ & 20 years & $1^{\text {st }}$ generation & University \\
\hline Griselda & Graduated & 20 years & $2^{\text {nd }}$ generation & Science teacher \\
\hline
\end{tabular}

The founders of the group, Claudia and Faviola, are sisters who came from Oaxaca more than 20 years earlier to seek a better life for their children. They were both educated as teachers in Oaxaca but took positions in restaurants when they first arrived as they learned English. Now, both are fluent in English and work within the school district. Claudia works in the main office of a middle school helping Spanish speaking families connect with school and resources. Faviola held a similar position while attending a local university to earn her social work license. She is now one of two district social workers.

Claudia's daughter, Ana recently graduated from a private university and is entering a teaching credential program to become a high school math teacher. Ana had many possibilities with her degree in math but decided to become a teacher. She shared that many professors at her university were surprised at her choice of career, telling her that she had "so many possibilities". Ana also believes that for many immigrant parents, teaching is not a career with much status, that in their quest for a better life, that better life did not include teaching.

Faviola's daughter, Griselda just completed a credential program in science and will be teaching high school in the fall. As a dance teacher, she is firm, strict and very 
focused. Griselda had shared a bit of her experience in the interview that sheds light on her vision for how teachers can have high expectations and get to know their students.

\section{Access to Participants}

The participants in this study are students in the district where I was a principal and now work in the central office. I've become familiar with the participants and their families through my ongoing support of their events and performances. I've attended their parent meetings and helped to organize dance performances at our local schools. In my current role, I have participated in meetings with the Mexican consulate to address fundraising and support.

Through my involvement in the district, I have also had opportunities to engage in informal conversation with parents and students at events. Those conversations have given me access to this study. Parents know that I'm interested in how our schools can support Latino/a students and their families. They are eager to share their ideas for this support and often seek me out with suggestions or recommendations.

As some of the participants are minors, the first step in gaining access was to share the research model with their parents at a parent leader meeting prior to practice. This is a regular meeting where parents organize upcoming performances. At this meeting, I shared the goals and design of the study before asking parents to consent to their child's participation. Following the parent meeting, I presented the study before practice to the middle and high school groups. After obtaining assent from the students, I set up 30 minutes for individual interviews to take place in the following 2-3 weeks. 
Once all students participated in an interview, they were invited to participate in focus group that was organized by grade span.

\section{Data Collection}

Data were gathered from standardized open-ended interviews with individual students as well as focus groups with the participants. Before interviewing the students, I interviewed the dance teachers, Maribel and Griselda, asking them about their experience as well as background on the group and the dance form. The individual interview consisted of 10 questions that asked the participants to share their experiences both in the group and at school. The six forms of Community Cultural Wealth framed the questions. The focus group questions prompted participants to think about both in-group and outgroup status. Some focus group questions overlapped with the individual interview questions. This design of the two protocols is purposeful in that students would have an opportunity within a group setting to revisit the questions they had answered individually. In addition to interview and focus group data, I wrote descriptive and reflective field notes following observations of the practices.

\section{Setting}

Interviews were held prior to Baile practice at the school campus in the library. The library setting for the interviews is important to the data collection as it is just down the hall from the Baile practice. The community of parents, students, and their families are gathered in different parts of the building, creating an environment that is exclusively Spanish speaking and that celebrates the cultures of Mexico. While high school and 
college-age students rehearse in the multi-purpose room, their younger siblings have class in the entranceway where they learn basic steps. Down the hall in Room 9, parents gather to plan for fundraising as well as to organize performances. Student tutors from the local university are in the computer lab providing lessons to parents on how to navigate the Internet. In the hallways, it is common to find parents and grandparents sitting on the floor talking while making some of the elaborate headdresses.

By holding interviews at the same school and at the same time as Baile practice, participants were in familiar surroundings and close to their community. This is an important aspect of the study design as I am asking them to reflect on how this practice, community, and setting support their understanding of community cultural wealth.

\section{Role of the researcher}

As the primary researcher, I maintained all recordings and transcripts from interviews and focus groups. In addition, I maintained field notes that are both descriptive and reflective. Data from recordings were transcribed and field notes were kept in a journal. As data were collected, I used a log to record emerging themes. The process of turning data into representations entails both interpretation and analysis (Denzin \& Lincoln, 2005).

All the research was conducted outside of the school day within the Baile environment. I had the support of the founders of the dance group, as well as their parent board in setting up interviews and focus groups. While some students began the interview in English, they often switched over to Spanish midway through. 
Based on my ethnicity and culture and status as an administrator, I am and always will be an outsider. As a White woman in my 50's, I look very much like many of the teachers and administrators in our district. My ability to speak Spanish sets me apart from other school staff and has given me more access as I often find myself translating meetings between parents and my colleagues. My Spanish is, however, still at the intermediate level and my accent is very "American". One participant, a recent arrival from El Salvador, couldn't understand my Spanish so I asked for help from another parent. Throughout the interviews, I mispronounced the names of the dances and made more than one reference to the "culture" of Mexico, without regard for the tremendous diversity within that country.

My role and ethnicity also got in the way. During the middle school focus group, two participants were apologetic to me when they wanted to share an example of racism by White students at their school. This made me wonder how much they didn't reveal based on my Whiteness. I have no doubt that my crossing the border was a disruption to the dance environment. However, I heard from parents and students that the single most important thing we White educators can do is to learn about and acknowledge the importance of the group to this community.

When I asked if this curriculum should be part of the school day, my middle school students were horrified. "This is my choice," said one, "I don't think anyone should be forced to do baile" High school and college age students had a different opinion, as did their parents. High school participants reflected on the lack of Mexican 
culture visible in their school setting. College students were disdainful as they reflected on their high school experience stating that teachers only knew them as warm bodies in chairs.

Parents see the dance group as a connection between their culture, their children and their community. When they learned about my position, they became prescriptive in their recommendations. Baile, they shared, is good for the brain as well as social learning.

\section{Data Analysis Procedures}

Data were analyzed first by looking for patterns within the transcripts of the interviews and focus groups. I used a constant comparative method (Glaser \& Strauss, 1968; Saldana, 2013). The patterns that emerged from this review included examples of how the dance environment provided a sense of strength and affirmation that was not always replicated within school. Another pattern came together around examples of negative experiences in which participants shared examples of being teased, harassed or ignored by their peers, community or teachers.

To better understand the patterns, I reviewed transcripts to make note of descriptive words or phrases. From this review, 43 initial descriptive codes emerged. In the second cycle of coding, I looked at the relationship between these initial codes. For example, the code "language" is frequently mentioned when participants spoke about their identity, family and interactions at school. Several students would start talking about an experience performing and then move on to describe how this led to someone 
making fun of Spanish language. Thus "language" as a code became part of two separate and broader themes.

The third cycle of coding led to the development of three themes. The initial codes and their connection led to themes that capture the participants' reflection on their experience in the dance and school. These themes reflect how participation and performance can deepen students' understanding of their identity and the world in which they live. The three themes are: 1) recognition of strength, 2) rejection, indifference, and inequity and, 3) identity and counter-stories.

\section{Summary}

The design and research questions support an exploratory study from which data is more descriptive than explanatory. Data from interviews and focus group surfaced descriptive codes leading to categories. The categories reflected larger and interrelated themes that illustrate how participation in Mexican folk dance has influenced students' understanding of their ethnic identity and the ways that identity can be both affirmed and challenged through performance. 


\section{Chapter Four: Findings}

This study explores the experiences of Latino/a students who participate in a Mexican folkloric dance group and how that experience impacts recognition of their cultural wealth. The proposition for this study is that through folkloric dance, these students develop a strong ethnic identity and an awareness of how that identity can be affirmed and challenged within racist environments. Central to this proposition is the acknowledgement that through dance, participants are performing and solidifying their ethnic identity for themselves and each other; something we rarely see in secondary school settings.

In performances throughout the community these student dancers wear trajes (outfits) representing indigenous culture while performing highly stylized choreography. Within the high school focus group, there was agreement that these performances could lead to unwelcome comments by their friends, teachers and even the community. This exposure to both affirmation and negative reactions seemed to build a stronger sense of their identity as well as awareness of racism within their world. Performance of their ethnic identity becomes a stage toward developing a critical consciousness and a form of taking action within a racist environment.

\section{Research Questions}

The research questions for this qualitative study support an exploration of the participants' experience within the group and at school. The questions are purposefully 
open to ensure that the study remains exploratory, avoiding any tendency toward a premature explanation of data. The first research question is: What is the experience of Latino/a students participating in a Mexican dance group? This question is designed to support grounded theory through a data collection process that elicits participants' reflection on their experiences. Through interviews and focus groups, participants had multiple opportunities to share what it is like to be a member of a Mexican folk dance group.

The second research question focused on the impact of this experience with folk dance on recognition of participants' Community Cultural Wealth. The interviews and focus group questions asked participants to consider different areas of cultural wealth or capital: aspirational, familial, linguistic, social, resistant and navigational. This question supports the proposition that participating in cultural activity leads to a stronger recognition of community strength.

The final research question prompts a comparison between participants' experience within school and the dance group. This study is designed to provide information to educators about how they might increase equitable outcomes for their Latino/a students. Given this purpose, the final question guides the study toward an illustration of the potential within cultural activity to support greater educational outcomes for Latino/a students.

These research questions surfaced the lack of opportunity for Latino/a students to develop an ethnic identity within school settings where their culture is not represented in 
the curriculum, teacher ethnicity or instructional model. Through exploring the experience of Latino/a students participating in cultural activity this study demonstrates how the arts can support ethnic identity and a critical consciousness that leads to greater outcomes for underrepresented students.

Chapter two reviewed the literature on ethnic identity development through dance and the impact of ethnic identity on increased student outcomes. The literature reviewed includes studies of how ethnic identity can be fostered through school and community groups and the impact of that identity on academic achievement, engagement and persistence. There were very few studies that connected dance, ethnic identity and student outcome and even fewer studies that connected dance with critical consciousness.

The research questions and design of this study fill a gap in the literature by examining how student dancers make sense of their world through the theoretical frameworks of Community Cultural Wealth and Critical Consciousness. In conducting this study, my goal is to explore the importance of cultural activity in supporting students of color. The racism they may experience in response to performances is an outward expression of the implicit bias they experience on a daily basis within environments where their culture is not represented, nor their identity affirmed.

This chapter begins with an explanation of data analysis processes leading to the conceptual framework. The conceptual framework illustrates the themes that emerged from analysis of the data that included interviews, focus groups and observations of practice. In reviewing my field notes, I made note that many of the observations were 
about the dance environment. These observations reflected on the physical space, interactions between participants and prevalence of Mexican culture and language. Given the prominence of environment within my notes, the first "theme" in this chapter is the setting of dance practice with subthemes representing the different elements of that setting that create a space where students and their families are affirmed.

\section{Conceptual Framework}

The conceptual model begins with the experience of students participating in a Mexican folkloric dance group and the impact of that participation on their ethnic identity development and recognition of cultural wealth. Questions drew on the theory of Community Cultural Wealth (Yosso, 2005) and elicited student reflection on their experiences within the dance and school community.

Data were analyzed and coded leading to the development of three themes: 1) recognition of strength, 2) rejection, indifference and inequity, and 3) identity and counter-stories. Each broad theme has subthemes that illustrate the varied context in which the theme emerged. Strength as an overarching theme breaks off into subthemes that overlap with assets defined through the theory of Community Cultural Wealth. The section on negative experiences captures the participants' perception of how the school system and broader community create barriers to equitable outcomes for all students and families. Subthemes in this section are specific to teachers, peers, and community. The final theme of identity and counter-stories reflects participants' understanding of the 
impact of their performance on both affirming their cultural identity and confronting injustice.

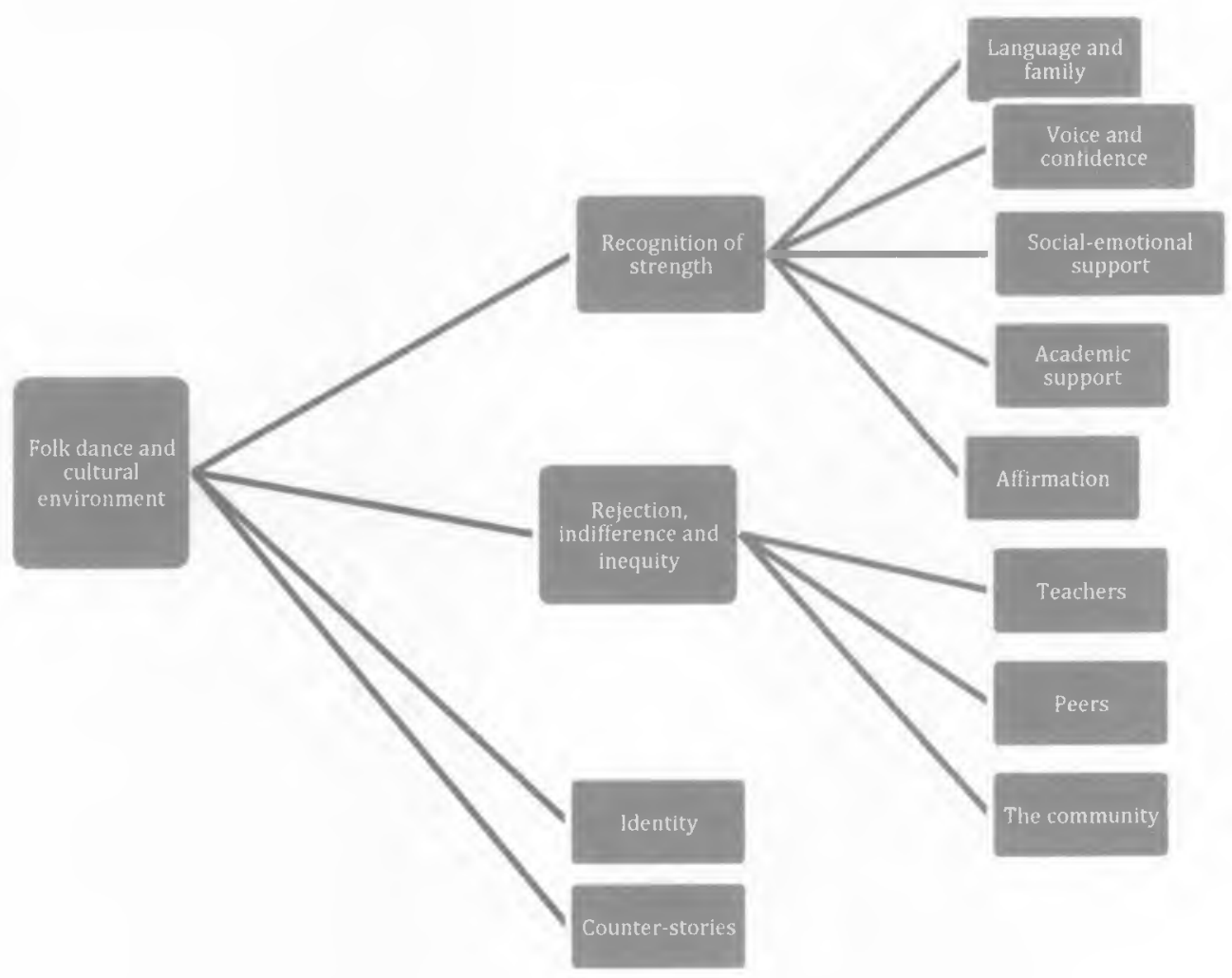

Figure 2: Conceptual Framework

\section{Dance practice as a culturally affirming environment}

A description of the dance environment is important to this study. During afternoon and weekend practice, Midtown Community School becomes a Plaza Comunitaria (community center), where every inch of the first floor is dedicated to dancers and their families. When I first observed dance practice five years ago, I was struck by the difference between the environment during the day and after school. 
Walking through at 9:30 AM on a weekday, the hallways are sparsely populated; used only for walking to and from the office, library or classrooms via the staircase. There is not much conversation in the halls with the exception of a campus supervisor asking students where they are going and why. The co-principals and school secretary have offices toward the rear of the hallway, not visible to those entering from either front or rear entrances. The attendance office that connects to counselor offices is more accessible to parents and students. Coming up the stairs during the school day, the halls appear vacant and visitors must travel a bit to find staff.

All of this relative quiet and calm shift after 4:00 on weekdays and 10:00 on Saturday mornings, as dancers, their families and teachers fill the library, auditorium, hallways and classrooms. To better understand the impact of this transformation, this section provides detailed information from field notes and interviews about the environment in which dance practice occurs and the impact on participants. The sections below describe the physical space, dance teachers, the activity and language spoken.

\section{Physical Space and Comfort}

Algunos niños nos han dicho que "Yo voy al grupo por que es un lugar donde puedo quitarme mi stress, olvidar por un rato que tengo problemas en mi casa. Estoy aquí y soy yo"

[Some students have told us that "I go to the group because it's a place where I can release my stress, forget about my challenges, or that I have problems at home. I'm here and I'm myself'] (Griselda, dance teacher) 
The factors that contribute to a setting in which students can be themselves are varied and complex. As participants talked about practice, their responses included details about school, teachers and the environment. That sense of feeling "at home" also came up in my observations of practice. In part, this has to do with how the community uses the school space. While dancers practice in the auditorium, students, their parents and siblings make themselves comfortable in hallways and on the stage. Mothers are most often in small groups chatting with their hands occupied by headdresses, skirts or other manner of costume that needs repair. Those with small children have their eye on the location as children alternately spring down the hall or squeeze in to the auditorium to watch the big kids dance.

The few chairs in the hallway are for grandparents. Parents and students frequently check in on them. When there is food, someone always brings them a plate. The small stage in the auditorium is where students wait their turn to practice. It is littered with backpacks, practice skirts, and sprawling teenagers who are often talking, texting and turning pages in a textbook. There are times when all talk stops as the students pay close attention to the direction of the dance instructor.

As participants arrive for practice, young men and boys often start a pickup game on the basketball courts. Claudia and Faviola greet everyone from the top of the stairs, directing parents to computer classes and students to dance or tutoring. Most recently, two moms have begun selling quesadillas from the top of the stairs with black bean paste, 
cabbage, and cilantro. The funds from food sales go to provide costumes and scholarships.

There is a strong sense of belonging conveyed by the presence of so many family members engaged in a variety of activities. As parents and children arrive, the teachers, and members of the board greet them with a handshake. There is no slipping by unnoticed, as I had tried to do early on. I've learned the importance of giving time to this greeting and slowing down to find out how the week is going from parents, former students and dancers.

Last fall on my way in to interview students, I fell in behind a family of five who looked to be new to the group. When we reached the top of the stairs Claudia immediately interrupted her conversation to come over and greet them. As they introduced themselves, the daughter looked around nervously. At the conclusion of the conversation, Claudia walked the daughter into practice and the parents went down toward the computer center, with the brothers who had started the punching and pushing that happens when brothers are walking together. When she returned Claudia had a gleam in her eye as she told me the name of the school where they came from. "We are growing" she exclaimed with pride. It was clear that the group's influence is extending beyond our school district.

I was struck by the fact that within minutes, this family could join a group without need for translation or forms to complete. Within some of our schools, translation and 
documentation may present impediments, if not a sense of difference that is less than welcoming for Spanish speaking families and their children.

\section{Teachers (Maestras)}

As this family's daughter went to her first practice, there is no doubt that she was given little time to observe. The dance teachers expect full participation of their students and would most likely have paired her up immediately with a more experienced dancer. The two teachers, Maribel and Griselda are kind and strict as they alternate between demonstrating the choreography, observing and critiquing. "Strict" is the word dancers, particularly the middle school girls, use to describe their teachers. They use this word to describe having high expectations and I'm not surprised that they are smiling when they describe their teachers as "strict". These high expectations convey the importance of the dance and the students seem to enjoy being part of something that is important.

The dance teachers arrive at practice from their work or school and Maribel has often just picked up her daughter, Xochitl, from childcare. They both often stop a dance, pausing the iPod that plays the music several times to review steps for reasons that are not discernable to me. I've known Maribel for more than seven years as someone who works in the office of one of our schools and Griselda is a former middle school student of mine who is finishing her teaching credential.

Both Maribel and Griselda have a presence that is strong and commanding. They are completely focused on the dance and don't hesitate to give constructive feedback. Their dedication to dance and their students is evident in the commitment to each aspect 
of the choreography. They rarely raise their voices, relying instead on tones that evoke discipline, commitment and expectation. Students attend to every instruction and it's rare that either teacher needs to refocus their group.

Maribel danced in Oaxaca before coming to the United States as a 13-year-old. Her talent set her apart from other dancers and she was named Diosa de Centeotl (goddess of corn) in 2008 for the Guelaguetza celebration. Guelaguetza is a cultural celebration in which representatives from the different groups in Oaxaca come together to share dance, music and food from their culture. The young woman who is named Diosa de Centeotl has an important role in the celebration and Maribel's knowledge of her culture and talent as a dancer earned her this role.

Every year, Maribel participates in dance trainings in Los Angeles where her talent is recognized. She is small and brown skinned with features that reflect her ethnic identity as Zapotec. Although small, Maribel has a powerful presence in rehearsal and on stage. She constantly scans her dancers picking up on any missteps. Away from practice, students shared that Maribel will talk about her experience as a dancer and encourage them to follow their dreams. She told me she would like at least one of her students to pursue dance in a professional company and knows firsthand how difficult this dream can be.

Away from the dance environment, Maribel has a quieter presence but one that is still strong. In a school office, she provides support to students and families. Her role during the day is to ensure access for Spanish speaking families and students within an 
English dominant environment while after school she strives to connect students with their ethnic identity through dance. Her daughter is in kindergarten and Maribel is restarting her studies in college on the nights she is not leading dance practice.

About her experience dancing, Maribel shared

[El ultimo que me recuerdo es que estaba yo bailando desde muy chica. Es que, como se dices esto - es una parte de tu vida, you do it because you just do it] The last I can remember is that I've been dancing since I was little. It's like, how would you say it, it's part of your life (Maribel, dance teacher).

Every aspect of her work as a teacher illustrates that connection to dance and her hopes that the students will develop pride in their culture and continue their studies.

Griselda was born in the United States and began dancing in middle school through family connection (her mother is one of the founders). She progressed to dance teacher while in high school as the group grew. Like Maribel, Griselda sees dance as a way for students to understand and develop pride in their culture. Griselda has a quiet intensity that is evident in both her role as teacher and a student in the university. As a newly credentialed teacher, Griselda has shared with me the importance of cultural competence and makes note of the ways other teachers could do better by their Latino/a students. She criticized teachers who don't get to know their students and who fail to bring those students and their interests in to the curriculum.

Both Maribel and Griselda hope that dance will lead to leadership skills, an opportunity to go to college and pride in their culture for their students. When I asked 
them what they wanted for students Maribel included that she wanted them to be ...proud of being brown, Mexican, short... I mean you just have to be proud of who you are and where you came from. This made me wonder if that was part of Maribel's own journey. Coming to the United States at the age of 13 from Oaxaca couldn't have been easy. Dance provided a connection to the people and cultures of Oaxaca at a time when she was immersed in a new culture.

\section{Activity}

One evening in the fall, I observed a student arrive with a Forever 21 shopping bag from which she pulled out new skinny pants. There was a lot of exclaiming as her friends admired the pants and asked about the cost. A few minutes later that student and her friends took practice skirts out of backpacks for the dance Flor de Pina. They pulled skirts over skinny jeans, arms extended to illustrate the skirt's beauty. The younger children, darting in and out, occasionally pause to watch the big girls dance. This interaction over skinny pants juxtaposed with the traditional skirts of Flor de Pina illustrates the dancers' ability to shift back and forth between two cultures seemingly without much thought.

As the middle school practice is wrapping up a few high school boys stroll in and gather on the far side of the room. Their demeanor is friendly and focused. At another practice, these same three young men occupied the farthest end of the hallway as they rehearsed steps for Calabaciados, the newest dance the group learned this year. One of the dancers had missed practice and the two students patiently walked him through the 
steps repeatedly until he appeared more confident. In interviews and the focus group, two of these students had shared that their friends at school often tease them about dancing. Within the practice environment, they appear relaxed and comfortable. Their interactions with each other signal a strong relationship.

While the activity in the auditorium is exclusively connected to dance, down the hall, the library is set up with tutors to help students with homework and provide classes in computer use for parents. As I walk through, parents are using the Internet to search Craigslist for a used car, or studying for their driver's license or GED in Mexico in all the ways that most of us use computers at home, yet many of the families share housing with other families. An entire family may have one or two bedrooms and common areas are often converted into bedrooms as well. Thus the dance practice provides a place for parents to catch up on email, take care of business and enjoy some space.

Our district provides space at two different school sites to the group without charge and for the most part, without too much interference. On Wednesdays and some Fridays, the middle school auditorium, library, and foods room are available to families and students. The alternative high school site is the spot where multiple activities are scheduled on Friday evenings and Saturday mornings.

The administration and support staff at both of these schools are sometimes called in to help out with the types of small "emergencies" that can happen with larger groups. One evening, while I was interviewing some parents, a small child pulled the fire alarm. 
The school's principal, who was staying late, helped with resetting the alarm and reassuring fire fighters.

This is but one example of many that reflects an informal partnership between the school district and dance group. Each year, a few of us have tried to expand our teachers' and administrators' awareness of this group and the work they do to support students. There is a small group of staff who show up to every event and a larger group who are often too busy to attend. The fact that much of the group's activity is unknown to the majority of our district staff is a cause of concern. However, the group's founders and board have been able to connect with local universities and the Mexican embassy to garner much needed resources, both human and financial.

There is an ongoing need for access to academic support and technology for dancers, their siblings and parents. To meet these needs, tutors from the local university sit with younger students or help adults with navigating the web. While their support may look like academic tutoring, I've seen tutors help students put together science fair display boards and look for images on the computer. When my children were in school, they did these activities in our home where they had access to a computer and parents with cars to pick up the last minute supplies for school projects. I'm reminded that for many families, living space may be limited to a bed where multiple family members sleep, a sink and shared bathroom.

In room 9, the parent board meets to review plans for upcoming events, the balance of their funds and needs for additional costumes. This group is committed to 
authenticity in both choreography and the outfits. Often this means commissioning someone to sew costumes or commission from a seamstress in Mexico. Decisions about how much to spend while saving funds for scholarship are part of the parent meetings. In addition, parent leaders and board discuss upcoming events and opportunities to promote the group.

\section{Language}

Language helps define the environment during the school day and in dance practice. During the school day, school business and instruction are primarily conducted in English. During dance practice, instruction, social interaction, tutoring and board meetings are all in Spanish. This distinction does not go unnoticed by the participants. One of the dance teachers pointed out that the use of Spanish in an "American" school is not always welcome or encouraged.

Aunque muchos de los niños hablen ingles siempre estábamos hablando espanol, (durante el taller), no ofende alguien que no entiende ingles o espanol por que nadie va decir que "No puedes hablar espanol por que este es una escuela Americana"

[Even though many students can speak English, we always speak Spanish (in dance practice). It doesn't bother anyone that some people don't understand English because nobody is going to say "You can't speak Spanish because this is an American school"] (Griselda, dance teacher) 
Maribel works in the office of a school in this district and her principal has repeatedly asked her to speak in English to a co-worker who is also Spanish speaking. Although her administrator has shared the context for this request (concern that other employees will feel left out), the admonition to speak English only is a sharp contrast to the dance environment in which Spanish is both the language of instruction and the social language between family, friends and community.

Two of the college students noted that they were also told not to speak Spanish in the school office where they worked. This admonition came from their monolingual, English-speaking supervisors who expressed concern that speaking in Spanish would alienate the others. In both the high school and college students' stories, monolingual students and staff acknowledged the power of bilingualism. However the admonitions against Spanish language use in school reflected the English speakers' mistrust of how bilingual students used their power or strength.

How participants use the space, their interactions and even their language are all significant to the development of each student's sense of self and community as they perform ethnic folk dance. The themes that emerged from interviews and focus groups show a strong connection to student experience within the environments of dance practice, school and performance space. The three themes that follow reflect the strengths and challenges that accompany performance of ethnic identity, particularly an identity that can be marginalized within school and society. 


\section{Theme 1: Recognition of Strength}

I've seen so many young women and get out of the dance group because they are in college and then have their diploma and then their masters and then their $\mathrm{PhD}$ and it's like amazing (Flor, high school).

Recognition of strengths emerged through rich description about the positive impact of the group. Interwoven within this description is the participants' sense of power from connection to their family and the community. They shared examples of strengths with stories about their families, the group and those who have moved on to college. As a junior in high school, Flor is very focused on her next steps and sees the dance group as a springboard to success after high school. Subthemes in this section reflect the theoretical framework of Community Cultural Wealth, particularly the themes of language, family, and social support. Strengths within their culture are often shared with examples of resistance that will be more fully explored in the third theme.

\section{Language and family}

Language surfaced in different responses as participants described a shift in their status and relationship based on the language skills and policies of adults including teachers. This is not surprising given that the dance environment is conducted exclusively in Spanish as compared with the English-only environment at school. Language then became a focal point for acknowledging the two worlds in which dancers participate. For example, all students described a strong connection between their parents 
and even grandparents based on retaining their Spanish skills. They also talked about having the ability to go back and forth between Spanish and English with their friends.

I prefer sometimes with my friends we speak Spanish and we completely doze off and forget and then we're like "When did we start speaking Spanish?" And then we just like stay speaking Spanish. (Jasmine, high school)

Closely related to language was the mention of family and relationship. All of the participants spoke Spanish with their family members and related how this gave them a connection to stories about their culture, family and past. During the focus group with middle school, there was a great deal of animation around language and relationship.

I really like speaking Spanish because Spanish is my first language; I was born only knowing Spanish and gradually learning English. So like when I can't speak Spanish it makes me sad because I like speaking Spanish a lot, more than English. And my parents are like you're going to forget your English. But I wouldn't want to lose my Spanish (Maria, high school).

Another student shared her concern about family members who had "lost their Spanish" and could no longer speak with grandparents.

My grandma she only speaks Spanish but my cousins they don't learn Spanish and my aunts and uncles don't teach them Spanish... when I talk to my grandma they can't talk a lot because they don't speak Spanish (Xochitl, middle school) 
Speaking Spanish was seen as an asset for students, connecting them with friends and family. There were also references to Spanish language as strength beyond social settings. All four of the high school students and three college students referenced being bilingual as an asset for their career goals. In addition, one high school student shared that her language skills helped her to support other students with new vocabulary. Well I love it and ever since I was little my family has told me to embrace that because I'm very lucky to be able to speak two languages and that it would benefit me later in life and so I'm always really grateful to be able to speak two languages, because in school it helps me sometime with the vocabulary because I can relate to things. One small example is that some words are similar and also because I get to help people that might not know one language or the other. I just love how I can relate to both of them. (Flor, high school)

Flor's pride is evident both in reference to future goals and her current situation. She reflects on how being bilingual gives her greater access to opportunity and skills that are immediately transferable in school setting. Another high school student shared the benefits and being bilingual with reference to her next steps outside of high school.

When you go to school and you're bilingual, it's a lot better for you ...because you can interact with other people and get awards which are better for college. You get more job opportunities. I think it's a gift being able to speak two languages (Belen, high school). 
For these students, being bilingual is a personal strength, connection with their parents and increased opportunity. The conversation about language also surfaced the ways in which Spanish language use creates tension at school. This tension may stem from formal or informal guidelines that maintain a monolingual setting at school. While speaking and understanding Spanish strengthens their relationship outside of school, within the classroom or school setting, Spanish language is subject to suspicion from monolingual staff. In their focus group, the high school students shared an understanding of when they could speak Spanish at school and when they shouldn't. This started with noting that they spoke only in Spanish in the dance environment but with the same group of friends spoke in English in social settings at school. However, in the classroom, several students described incidents where teachers chastised them for speaking in Spanish. The teachers made assumptions that they were taking advantage of monolingual students to talk about them in a negative way.

Some teachers are against it like in class, they are like "Ok, no Spanish no other languages because like blah, blah bla". Kids confuse that. For example I sit next to a Mexican kid and a kid who doesn't speak Spanish. But the Mexican kid and me we speak Spanish. But then there's that one kid who can think that we are talking about them and so obviously they tell the teachers who are like "No, no Spanish at all. Like, you guys can't speak Spanish in here". It feels sad, because we wouldn't really do that. Again, they think that since they don't know 
the language then they don't know what we are saying. Yes, there are some Mexican kids who do talk about people but I don't (Carlos, high school). Carlos's observation about the monolingual teacher and student being "confused" or misunderstanding when he and another student spoke in Spanish presents a contrast with the sense of strength students shared when they talked about future plans and connection to family. Here, Carlos points out that rules are made from a place of ignorance and assumption. He is "sad" that his teacher would assume that he is using Spanish to speak poorly about another student. Rather than recognizing the linguistic strength of bilingual students, these students were made to feel guilty for using the language that connects them to their community and culture.

Language came up as well around the unfamiliarity with indigenous words that define dances and specific steps. When dancers tried to share the names of dances with students or adults, their explanations were often met with mockery, not only from English speakers, but also from Latino/a students outside of the dance group.

Dance practices and meetings are conducted entirely in Spanish, further connecting participants to their first language. The dance environment reaffirmed language as a strength while school presented language as a problem. Students made note of how they adjusted based on the environment, however they strongly believed that retaining Spanish was important, even if those with power did not agree. 


\section{Voice and Confidence}

While several students credit the group with helping them overcome shyness, there was a common theme around the way that performance helped them become more confident. Four of the middle school students, two high school and two college students volunteered that they had been shy and quiet before joining the group. Rehearsing with the dance group helped with their confidence both in school and in performances. One of their teachers made note of the difference between students' persona on and off stage. there's a lot of students if you see them on stage you never would think it's like them so once they get off stage it's like they're shy. They become a different person and you can see that they love to dance through their expressions (Griselda, dance teacher).

Griselda's observation was confirmed by several students who described their transformation from being shy or quiet to developing a new persona through performance.

I started when I was in $6^{\text {th }}$ grade I joined the group by force (from her parents) I did not want to dance. I was really intimidated by everyone and everything. When I joined I started to gain confidence. You learn from your mistakes (high school focus group).

This comment could connect to any performance whether dance, music, or drama. However, the middle school students shared an observation about the nuances of 
performing specific dances and what teachers told them about the characteristics of specific indigenous groups. In describing the steps of one of the dances, Maria remembered the guidance they received from their teachers and the insight she gained from this instruction regarding women of that region of Mexico.

They're (the women of Oaxaca) not scared to use the machete. They told us when we started dancing it that they are brave, independent strong women and so they have a strong attitude and they are not scared of doing like anything. And so we have to show that in the dance because people are from there and they are expecting it to be like the way they dance it (Maria, middle school).

Maria's observation illustrates the ways in which they are performing their ethnic identity and that of people in the audience. She and the other dancers must make a show of strength within their performance based on their understanding of the characteristics of women from Oaxaca. Taken together with the other observations about developing confidence, we might infer that their public persona in these performances helps build their voice and confidence outside of the performance.

The developing confidence was described not only in contrast to being shy, but also in response to teasing within their school environment.

One of the benefits is that when I was younger I was in elementary when I went through bullying and so I was very shy very timid, really introvert I didn't want to talk to people and that is one of the reasons as to why I didn't really want to join the group. I was scared of what people thought about me but once I joined 
I saw that people had different levels of dance whether they were really good or not so good and other people had challenges too so I wasn't the only one. So when I started joining the group, every one had different levels and no one judges and I started being really open and not the same any more (Jasmine, high school).

Belen and Carlos both agreed that being part of the dance group made them more open and less shy. Belen describes how performance helped her to be proud of her culture.

I'm still like really shy when I do class performances or like presentations.

But now I'm a lot more comfortable with my environment and I'm also proud of my culture, of where I'm from because a lot of people here aren't maintaining where they're from where their blood is from and I find it really important to keep being proud of where you are from (Belen, high school).

This subtheme presents in contrast with the themes in section 2 where students explore instances of being made fun of for their performances. By putting their ethnic identity on display, they are garnering negative responses as well as developing a sense of strength.

\section{Social-emotional support}

Some are there because they just love to dance and also because it's just a place they can belong you know it's a safe place where they can be someone else and be themselves. You're around our own people (Maribel, dance teacher). Closely related to developing voice is the subtheme of strength through community and support. This subtheme emerged as middle and high school students 
made reference to a sense of comfort within the group as compared with the environment at school.

You feel more comfortable also and I think that's where it's different from school. You feel more comfortable being there and that's why sometimes you don't express that in your own school setting (Griselda, dance teacher).

Carlos also made a comparison between the sense of support at practice and at school. Here it's more like a family. Like if they see that you are struggling they help you or see if there is someone else who can help you and I don't see that very often in school.

In my observations, Carlos stood out as someone eager to help other students. He has mentored one of the newer dancers, helping him with choreography when the dancer missed a practice or two. Carlos is not the only student or adult going out of their way to help. Dancers scramble to find substitute props for those who forgot them at home. They lend ribbons or an extra practice skirt. This sense of shared community was also communicated through the focus group meetings. While there were a couple of students who talked more than others, they were eager to bring the quieter students in to the conversation, often pausing their own story to ask them what they thought. It was clear at both practices and during focus group interviews that the students derive a sense of strength from the support they both give and receive as a community.

This support can also take the form of lending an ear to or even providing counseling support to dancers who are struggling with depression or other disorders. 
Two years ago, the founders were worried about the unhealthy eating habits of several dancers. They worked with a local agency to bring in counselors who talked about the importance of eating well and maintaining a healthy weight.

According to the students and teachers, dancers feel comfortable sharing feelings of sadness or anxiety about school or home life. Maribel has observed the ways that this group provides a resource just by listening.

También, hemos recibido a unas que sufren depresión el grupo las ayuda es como una terapia para ellas y ellos. Estamos quitándole trabajo a los consejeros.

[We have had dancers who suffer from depression and the group helps them as a form of therapy. We are picking up the work of counselors.] (Maribel, dance teacher)

\section{Academic Support}

The founders and teachers are very strict that the dancers maintain good grades and keep up with homework. They check in regularly with students and their parents about their progress at school and don't hesitate to remove a student from practice to work in the library down the hall if they are falling behind. The library is kept open for computer classes while tutors from the local university provide help with homework. When the dancers spoke of this academic support they received in connection with dance practice they would reference contrasts with school. Several students referred to one of the founders as people who personally urged them to do better in school. 
I remember when Maestra Claudia, she helped me because I was getting really bad grades in middle school and she helped me. "Oh why do you have this grade?" And she would help me until I got at least a B in that class (Belen, high school).

The middle school students also spoke about the requirement that they do well in school. This created some challenges given that most of them had other activities outside of dance practice and homework. They shared their strategies for staying up later to finish or meeting over breaks during the school day to help each other out. One of the high school students who is the daughter of a founder spoke to the connection between the group and academic success.

Something good about the group is that they always put school before because that is what we are aiming for. Maybe many people don't know this but the group is to help kids who are going somewhere they shouldn't be. To join this (dance practice) and like to learn and appreciate the culture they maybe are ashamed of, scared of having or just like don't want to enjoy it (Flor, high school).

Flor gave a few examples of students who joined the group at a time where they had many challenges both at school and at home. The group, with its focus on both cultural activity and academic support helped students take pride in who they are and set goals for who they will become. 
The expectation that all dancers will go on to college sometimes contrasts with lower expectations at school. Two of the high school students spoke to the importance of advocating for more advanced classes.

My counselor wanted to put me in Intro to Algebra and I asked to be put in Algebra and they didn't want to. That's what kind of threw me off (Maria, high school)

It's really hard to fight because they are the counselors. They're your superiors and you can't do anything. If you find the right people if you find a different counselor, that's what helped me, I found a different counselor who said "I'll put you in a different class" (Erick, high school)

Both of these students advocated for placement in advanced classes, an expectation that align with the group's focus on college access for all students. Within the individual interviews, each student shared a goal of college and career. The students were very specific in what they are planning to do and all but one cited the group as instrumental in supporting their dream. The academic support the group provides builds a sense of strength and empowerment amongst the participants, allowing them to set goals beyond high school and meet those goals through community based support and recognition of their capacity. 


\section{Affirmation}

Students cited the response of audience members as another form of strength. In this case, they referred to specific incidents where members of the audience sought them out to share the impact of the performance. During the high school focus group, students compared stories of people approaching them after the show to thank and congratulate them.

“A woman said 'Are you from dance?' and she said that I dance good, or well. Another time someone's dad told me and Eric 'Congratulations for what you did' and they thanked us for the show in December" (Carlos, high school).

This was from the same student who shared earlier that his friends made fun of him when he danced at school. Although he had shrugged off their teasing comments, it was clear that the positive affirmation meant a great deal to him.

Another high school student shared that she and a friend were offered money by a parent after the show because he wanted to express his thanks. This incident impressed her, although she and her friend refused the money, suggesting a donation to the group instead. At the December performance I attended, most of the people in the theater were Mexican American. In the tradition of Mexican folk dance, they called out encouragement to the dancers, alternating between "gritos" (shout outs) and whistling (chiflar). I've learned that this is an expectation at dance performances and there are usually a few audience members who will start it off. The interaction between dancer 
and audience seems to energize dancers during the performance. Students appreciate the affirmation and recognize that the dances they perform represent the culture and experience of their families and community.

In summary, the data from interviews and focus groups shows that participation in the Mexican folk dance group gives students a sense of strength founded upon a deeper understanding of their language and culture. Students maintain their first language and gain new knowledge of their culture through choreography that depicts the culture and history of indigenous and mestizo people of Mexico. Students also recognized the strength that comes from developing confidence. Both the community support and affirmation at performance helped many of the participants become more confident and assertive, even when they took a stand contrary to that of an authority figure at school 


\section{Theme 2: Rejection, indifference and inequity}

Students recognized the impact of the group on developing their strengths as well as the negative experiences they experienced at school and within the community. This theme brings together the students' stories about being teased or ignored as well as their awareness of the bias within our community and country that contribute to systemic inequity. The negative experiences are explored through the subthemes of interactions with teachers, peers, and the community.

\section{Teachers}

A disconnect between family and school surfaces abruptly as students talked about their teachers in relationship to dance performances at school. The fact that most if not all of their teachers are White was presented as an observation, however Whiteness and teachers as descriptive codes were often intertwined. Participants described teachers at school as alternately supportive and uninterested. It seems that teachers are supportive with academic work; however, they made little effort to learn more about the students' involvement in the dance group.

The middle school students thought that one or two of their teachers might know about their involvement in the dance group but that for the most part, their identity as dancers went unrecognized after a weekend of performance at local events. One student gave an example of teachers asking about their weekends. She said this gave her an opening to share about a performance, however those opportunities are few and far between. 
A college student looking back on her involvement in high school shared her hope that teachers would recognize their students through their outside interests as well as their academic performance. She says,

To know that it's not just a body heating up a chair in their classroom it's someone that does other extracurricular activities and is a human being because a lot of times the teachers just view the students like "Oh this student is an " $A$ " student. They don't see them as a person (Maribel, dance teacher)

Several students cited examples of teachers throwing away flyers they gave them for dance performances. Other teachers were quick to turn down requests to buy tickets. There were a few examples of teachers who made the effort to learn more about their students, asking them to share about practice or performance. There were also teachers who came to performances. These actions resonated with the group as examples of teachers who cared.

While the younger students shared teacher response to their performances, the older students expressed more concern about misunderstanding and tension between White teachers and their Latino/a students. One of the college students said that her experience in the group made her more aware of implicit and explicit racism at schools. Because she and others were maintaining aspects of their culture, they were the targets of unwelcome comments from their peers.

Ana cited early experiences with feeling "different" in elementary school when her peers commented on the chapulines (cooked grasshoppers) she brought for snack and 
her long braids. She compares these experiences to her ongoing involvement in the dance group where she and other perform their ethnic identity to members of their own cultural group and the public. When eating a traditional snack or performing folk dance, Ana's cultural identity was on display and she found herself, at times uncomfortably aware of differences. Ana asked her mom if she could pack her own lunch, so that she could be more like her peers. She also stopped braiding her hair, again in an effort to be less "different" in appearance.

None of my other classmates wore their hair in braids and I wanted to be like them and so I told my mom I don't want to get my hair braided anymore. And without knowing it, I was losing those precious moments where we used to sit and she would braid my hair and she would tell me stuff. When she braided my hair she would tell me stuff about her dad, about her mom, kind of like small, chitchat stuff. And so those moments I will never get back. Those are moments that I lost because I didn't see myself in my classmates or in my teachers.

Ana and members of the dance group may be more aware of racism as members of the community respond to their efforts to maintain their culture. Unfortunately, the response of her peers led Ana as a young girl to attempt to assimilate into the more dominant culture.

Although Ana no longer ate chapulines or braided her hair, she maintained a connection to her culture through the dance group. Within the group, she could develop her identity with others, and make sense of those experiences in elementary school. 
I think I realized that, that (comments about chapulines) was racism when I entered $6^{\text {th }}$ grade and the group kind of took off and I was like "oh that happened to me" and I hadn't ever picked up on that.

Ana shared that within the dance group, participants began to feel more comfortable sharing negative experiences and realizing that many of them stemmed from racist attitudes amongst their peers and community. The dance group became a place for shared experiences and group identity building as participants recognized the ways in which their cultural identity could be affirmed and rejected.

So we're within these two worlds and then we're kind of creating a whole different world for ourselves. So that's why I think that the biggest act of kind of being able to cope and deal with racism is the fact that they are still even here because this is huge for them to be able to continue to do this (dance performance).

Ana's experience within the group led to a stronger understanding of race and racism. As a college student, she brought this understanding to observations about the ways in which professors and peers responded to race. She shared an example of how a White professor responded to a protest against racism on campus by not canceling class but letting students know that they could have an alternate assignment. Ana chose to stay in class, not feeling comfortable with the professor's admonishment that they were "there to learn" When the protestors came by the window of the classroom, the professor 
stopped her lecture and looked directly at Ana (who was one of two Latinas in the class). Ana felt uncomfortable with the professor singling her out in this way.

Ana connects her reflection on college experience to her participation in the dance group noting that she is more aware of the implicit racism behind behaviors and speech.

I think that my experience here (with the dance group), has allowed me to be critical and I think that is one of the biggest things that I've struggled with and it's allowed me to find my voice and to stop being afraid of things. I think up until high school I never said the color "White" when I referred to people I would never say "Oh a White person would do this" I would never say that. I think that the group has given me the confidence to say that's OK because you are describing someone.

Students also relate that teachers or professors often call on them to represent their community. Again, as members of a dance group, the participants are often the target of questions and observations both from the White and Latino/a communities based on the public nature of their performances. As they wear the outfits and perform indigenous dances they attract both attention and generalizations from outsiders.

\section{Peers}

Dance performances and media coverage of those performances provoked response from participants' classmates. Some of their peers had questions, while others made disparaging comments. As participants shared these interactions with their classmates, they often referred to the ethnicity of the student who initiated comments, 
making inferences about their understanding and bias. The peers' comments reflect both a rejection of the dancers, cultural misunderstanding and resentment over the attention they garner.

The middle school students shared several experiences with peers who they identified as Mexican and who made fun of their dance steps. Two participants said that they were so affected by these experiences that they would go out of their way to avoid the students who were making fun of them. One middle school student, in particular, stopped coming to school for a short time in response to being teased. She described the situation in this way:

I got bullied last year because I would have performances at my school and they would be like "that's so gay," and like then I didn't want to come to school for a while, and obviously I had to go, but I didn't want to go because I knew that that one kid that started it would just keep on going until like I couldn't hold it in. So I told my dad and we worked it all out. I did get bullied for a while and I just realized that I like to do it. It doesn't mean that they have to like that I do it. So I just... it got to a point that that it was so annoying that I was like you know what I don't care any more I'm just going to like ignore it and like you don't make sense so don't talk to me. If you are going to say bad things about what I do for my culture then just don't talk to me. No offense but it's more the White people that are kind of like "Why are you going to do that?" And that doesn't make sense. 
As the student describes the evolution of her response, it is evident that this negative experience has helped her think about why she dances. She states that the student is saying bad things about what she "does for her culture," illustrating what involvement in dance means to her. Her characterization of the teasing and probable bias of the student is an example of how negative experiences give the dancers a strong awareness of racism within out society

Another student shared an example where she confronted the students who were teasing her and another student.

...like there's these kids who got in trouble and so they had to go to dance and like we would go to school and me and Maria they would follow up because we hang out and so they would just hang out with us and they would say 'Oh that thing that you guys go to it's stupid and like it's retarded' and then like I got really mad at them and I said 'Like can you guys stop it?' And they were like 'What, it's true' and I was like 'You guys may not like it but it's something that me and Maria like to do so it's not fair that you guys are telling us that it's stupid' (middle school focus group).

In confronting the student who is harassing her, the dancer states that this is something she and her friend "like to do". The issue of fairness is not around racism or inequity. In this case, the student is focused more on her rights and that of her friend to participate in an activity they enjoy without being teased at school. This connects strongly with the 
theme of rejection as their peers made fun of the students' participation to an activity that clearly connects them to their culture.

While some negative interactions stemmed from performances at school, a series of stories in the local newspaper about the dance group provoked comment from peers as well. Both high school and college students reflected on how this publicity surfaced some negative comments and uncomfortable questions at school from their peers and a lack of response on the part of at least one teacher. One of the high school students, Jasmine offered an example of the type of comments she and her fellow dancers would hear at school.

I had people in my AP US history class and Belen and I were on the cover of the Chronicle. He said, "You Mexicans dancing that kind of stuff is really gay." I said "You know what that's your opinion I don't care what you say because it's what I like to do." We have the identity of "You are the Mexicans that dance" It's something I learned to ignore.

Jasmine's comment about her identity points to some ongoing tension between Mexican American students in the dance group and Mexican American students who have not maintained their connection to the culture or language of Mexico. This surfaces again in comments about the community where older students and teachers speak to assimilation as a way to get ahead in society. Within the school setting, dancers are noticing that participation in ethnic dance sets them apart from other Mexican Americans and can create tension or discomfort. 
At the local community college, one of the participants described a class discussion prompted by a classmate making a comment that Mexicans were always on the front page of the newspaper for something. The participant, whose sister was one of those dancers featured, took the opportunity to share about the upcoming event and invite the class to attend. While she thought the other student's tone was aggressive, she said It's easy for us to judge, but when you experience you get more knowledge. In this situation, the student chose to respond by providing more information. When I asked about how the instructor responded, Cecilia said

She let me talk and I guess she was not ready to have someone speak up. I think she pretty much let me talk about it. She highlighted that the newspaper focuses on what the public wants to see and that was important and that this was an important event.

There was some disappointment expressed by the focus group around the instructor's more generalized comment about newspapers and printing what the public wants to see. While Cecilia picked up on the racism within the peer's comment about Mexicans, the instructor chose instead to stay neutral. As this was a political science class, Cecilia thought it would have been a great opportunity to talk about the role of cultural events in deepening understanding of the diversity within her town. Her instructor's silence on the topic of race and culture was noticeable and stands out in contrast to the middle and high school students' more open advocacy for the group. 


\section{Community}

Within each of the focus group interviews, participants raised concern about the response they would get from members of the Latino/a community who are not part of the dance group. Their stories about the Latino/a community reflected the choices Mexican American families may make to survive within a racist society.

For me it wasn't really White people, it was Mexican people and like 'You guys are Mexicans. Why are you making fun of other Mexicans when we are just showing our cultures?' and I would say 'Yeah showing off because we like to do it. And it's like performances and then we have to put energy into them.' And I'm like 'You guys are Mexicans and you are making fun of other Mexicans because of their culture' And I'm like 'What if you guys did it, like what if it was the other way around and if you guys liked to do it and I would make fun of you guys?' (Middle School focus group)

In this example, the student points out the ethnic identity of the people making fun of the group. She begins by referring to "our cultures" which is more inclusive language between dancers and community. Interestingly, she uses the pronoun "their culture" when she talks about the performance. While she acknowledges that dancers and other Latino/a people have a common identity, she maintains that performance of that identity belongs to the group. 
Within the middle school focus group, there was much conversation about teasing while the high school and college age students made observations about the nature of that teasing and why it came from the Latino/a community. Ana shared

From the White community I don't know if we get as much backlash as we do from our Latino/a community and if we do I don't think that it's ever targeted directly at an individual more at the organization as whole (Ana, college student)

In an earlier section, Ana described how her White classmates and professor in college made her feel different based on the visible displays of her culture. In Ana's experience, White people see performance of culture as different whereas some members of the Latino/a community see this as a threat to their attempts to assimilate. She described how some Latino/a community members respond to displays of Mexican culture by teasing members of the group and how relationships with administrators (including myself) and her mother's position in the school district, helped buffer her from some of the teasing other students experienced.

I feel like I can't personally speak about being bullied because of the group because I'm Claudia's daughter. So you can't really mess with Claudia's daughter because of the fact that the group is supported by people like you (the assistant superintendent) by powerful people. So I think that I was in a way protected from being bullied because of the group because they were scared of getting in trouble or what not. But I think that it's more a source of "You're the 
Mexican that puts your hair in braid." "You're the Mexican that wears flashy outfits" so that's the type of comments we receive from our Latino community Ana's observation was fleshed out during the high school focus group as one of the students made an inference about why the Latino/a community may not be supportive of the dance group.

A lot of times we're not appreciated because of the fact that we're making the Latino community more prevalent and more visible within the community and a lot of Latinos don't want that. A lot of Latinos don't like that because they want to fly under the radar because they don't want to be associated with us because we're the Mexicans who actually own being Mexicans and we're the Latinos who actually own being Latino. They don't want that association. (Jasmine, high school)

The concern about that association is also present within the group. A few years back, the parent board created a Facebook page to provide updates on performances. Two of the teachers noted that there are dancers who will not "like" or "share" these events on their own Facebook pages. The teachers believe this is because the students have been teased for their involvement. The phrase "We are the Mexicans who dance" from high school interviews captures the difference between students who maintain a connection to their cultural identity and those who assimilate.

The difference between dancers and their Latino/a peers may be further exploited through some of the practices that were described under the second theme. When English 
is the only language spoken and there is little opportunity for Latino/a students to see their culture represented in the curriculum or staff, Latino/a students may not feel comfortable performing their identity. The next section addresses the impact of performance on supporting this identity and creating a counterspace within structures that privilege the dominant culture.

\section{Theme 3: Identity and Counter-Stories}

Participation in folk dance gave students a connection to their cultural identity and a stronger understanding of how their culture is misrepresented within the larger community. As individuals and part of a larger group, students consistently gave detailed responses to questions about culture, identity and family. The depth of their connection to a cultural identity was also communicated through a comparison between themselves and Latino/as who do not maintain that connection. This led to the subtheme of counterstories defined as the stories of those people whose experiences are not often told (Solorzano \& Yosso, 2005, p. 32). Within this subtheme, students expressed their desire to challenge the negative perception of Mexican Americans through performances that communicate their culture.

\section{Identity}

I'd say that it helps me embrace Mexican culture and I'd say we know a lot about where we come from (Maria, middle school)

Participants connected baile folklórico to ethnic identity in ways that were both explicit and implicit. Maria's statement demonstrates how participation in the dance 
group has helped her learn more about her culture and embrace that culture as her own. In individual interviews, students described themselves as members of several communities. Their identity was first defined through ethnicity. Of the 16 students interviewed, only one defined herself in more general terms as a "Latina". The other students identified as either Mexican or Oaxacan. Several students who are from state of Oaxaca further specified their ethnic identity within the region.

So there are so many layers for us it's hard again to always preface everything that we say by 'I'm from Oaxaca, I'm indigenous, I'm Zapotec and then I'm Mexican. Then I'm Latino/a and then I'm everything else" (Ana, college student)

Participants also recognized the diversity within being Latino/a and referenced the impact of that difference on communication and relationship. Several students pointed out that within regions or estados of Mexico there are groups that don't understand each other. There is Zapoteco, there is Mixteco, etc. For each region there is different types of Zapoteco because, like, my mom speaks one and la maestra Fe speaks another one (Maria, high school).

The way that students identify would indicate a stronger understanding of their culture and ethnicity. Through studying baile folklorico, the students are learning more about the values and experiences of indigenous and mestizo cultures in Mexico. This identity is often referenced as students talked about performance as a way to present their identity and culture within a racist society. 
As I reviewed transcripts of interviews and focus groups, another interesting pattern emerged with regard to how students identified themselves and members of the broader community. Members of the dance groups state their identity as "Mexican" while the broader community is "Latino/a". Most notably, this came up when two different students described how they believe others see them. Participants shared that their peers see them as the "Mexicans who dance" and "The Mexicans with big skirts". The use of the term "Mexican" in the interview transcripts has the connotation of someone who is holding on to their cultural identity.

When talking about the larger community, particularly those who do not support the group, participants described them as "Latino/a". In doing so, the dancers seem to ascribe the quality of someone who has lost their connection to their culture. Jasmine uses "Latino/a" several times when she describes members of the community who want to "fly below the radar". Ana also uses "Latino/a" to describe people in the community who have tried to assimilate into White culture. The alternating use of "Mexican" or "Latino/a" in the participants" responses seems to indicate their perception of how an individual or group has maintained a connection with their culture. Clearly, for the dancers, being "Mexican" is preferable to "Latino/a", as it describes their commitment to maintaining their cultural identity.

\section{Counter-stories}

This subtheme emerged as students reflected on negative comments from both the Latino/a and White communities. While I expected the older students to have an 
awareness of racism, it was surprising and disheartening to hear middle school students discuss Donald Trump and his influence on public opinion about Mexican Americans. I had underestimated their exposure to Trump's statements about immigrants and the need to build a wall between Mexico and the US. These comments came up in the focus groups and while only a few students shared their thoughts about Trump, every student was nodding and laughing, sometimes uncomfortably.

The response of students to rejection, indifference, and racism illustrated their belief that dance could be a form of resistance by challenging dominant negative perceptions and narratives of their culture. Discussion of cultural pride emerged from stories of being teased. Several students made statements that showed their belief that pride in their culture set them apart from other Latino/as who are not "maintaining their culture." One of the high school students conveyed the importance of maintaining and expressing cultural connection and pride.

In my opinion, I think that being a member of the dance group, we really learn about our culture and about where we were born and to be able to express it ...yeah I think that's one of the most important things (high school focus group) Thus, overall the expression of pride in their culture through performing folk dance is presented as something of value to the participants. However, several students took this further to explain how their performance counters a negative perception of Mexican American people in the United States. Here are examples of three of the high school students: 
I also think that some people have this stereotype about Mexicans that we are going to be terrorists...Like Donald Trump....That we're bad people (Belen, high school)

Not all Mexicans I'm not going to be like there are some Mexicans that are like not the best examples to represent the community but like us we're good representations of the Mexican community and I'm proud to be like I'm actually really proud to be Mexican so when people say stuff like start like offending that I'm in this dance group and saying that I'm Mexican I just say that if you really have nothing good to say about me right now then just don't say anything (Xochitl, high school).

I also think that that is a good example of showing for example showing a person like Donald Trump like we're Mexican and we're really good examples for other people who are Mexican but who aren't really showing it and want to show it and stuff like that. It's like we have to show other people what our culture is like and that how we are and we're not all bad because there are white bad people. There are White serial killers, there are robbers... (Jasmine, high school).

These observations surfaced in both the middle and high school focus groups as students considered the impact of their participation on both Latino/a and White 
communities. Counter-stories can challenge dominant negative perceptions of Mexican Americans and serve to provide new strength-based stories of social solidarity, cultural affirmation, and community bonding to preserve cultural and artistic values and practices across borders and contexts.

Belen points out that in recent public debates Mexican Americans have been portrayed as rapists and terrorists, most famously by then current presidential candidate Donald Trump. She acknowledges the power of this public statement on influencing people within the community and looks to dance as a way to counter that influence.

Xochitl and Jasmine add to Belen's statement by pointing out that not all Mexicans are representing their culture in a positive way, just as not all White people are good representatives of their culture. Jasmine, in particular, points out that as Mexican Americans, they feel a responsibility to disprove negative perceptions. This responsibility seems to weigh heavier on the students as they compare themselves with Latino/a who try to assimilate within the White culture.

\section{Summary of findings}

These three themes captured the experiences of students participating in a Mexican folk dance group. Rehearsals and performance gave them a stronger sense of their cultural wealth, while paradoxically, also exposing them to negative experiences through encounters with racism related to their participation in cultural dance. These experiences led them to reflect on the importance of dance performance as a way to counter racism and affirm their strengths. 
Across all three themes, students shared a sense of their Community Cultural Wealth (Yosso, 2005). The dance group promotes Spanish language proficiency and honors the culture of students' parents. Recognition of their linguistic and familial wealth surfaced both through a sense of affirmation and their response to racism. Students delighted in the fact that they could speak with family members, including grandparents, in Spanish. This sense of joy extended to their ability to switch back and forth with other bilingual students and provide support for students who were learning English as a second language. Students also shared that members of their families had learned folk dance in Mexico and so their participation in cultural dance here in the US gave them another level of connection to family. Clearly, an opportunity to dance in the United States was a source of pride for them and their families. They saw this connection to family and language as leading to success in and beyond school. Awards, scholarships and promising careers were all mentioned as outcomes for maintaining their first language and connection to culture.

Language and family as strength also came through students' description of interactions with teachers and administrators who asked them to speak only in English. The idea that teachers thought they would use their first language to make fun of monolingual students was saddening to the students. Similarly, teachers' lack of acknowledgement of dance performances felt like a slight for students, their family and culture. These negative experiences did not lessen the students' sense of family and 
linguistic strength. Instead, they increased students' awareness of behavior and attitudes that reflect racism within society and at school.

Recognition of social and navigational wealth was closely intertwined as students described support they received within the group. Social capital is the connections to community resources that will help them navigate difficult situations. Navigational capital is the knowledge and skills that, in this case, are developed through their social connections.

The findings show that participants in the dance group have an understanding of their social and navigational wealth. Social wealth within the group is communicated through high expectations, assistance with academics, counseling and sense of community. The dance teachers state that these supports were part of the group's mission drawing on observations about challenges for Latino/a adolescents within schools where their language and culture are not represented.

Dance teachers hold high expectations for academic achievement and point students toward the resources provided by the group. Students are excused from practice to finish homework or to be tutored in the library. The only requirement is that they maintain a commitment to being at every practice.

The group also recognizes the impact of stress on students and has started to look for community resources to meet this need. Teachers and students spoke to the importance of the group as a community where students could be safe. Students describe 
the dance environment as a place where they get support, can share experiences and can let down their guard.

Knowledge of their navigational wealth emerged as students shared their strategies for responding to the pressures of dance practice, school and performance. Participants' ability to respond to difficult situations, carve out time for academic commitments and set goals for their future all reflect this area of Community Cultural Wealth. Knowledge of navigational wealth was clearly impacted by the expanded role of the dance community. By giving students opportunities to complete homework and get academic support, the group is also prompting them to set and maintain high expectations for their work.

High expectations and negative public perception of Mexican Americans are also explored through knowledge of aspirational and resistant wealth. Aspirational wealth is the strength that comes from setting goals and maintaining hope even when confronted with barriers. Resistant wealth is the knowledge and skills acquired through confronting those barriers. Student recognition of their aspirational and resistant wealth was communicated as they shared their response to those peers in the community who made fun of their culture and/or performance of their cultural identity. These responses varied from middle school students telling their peers to leave them alone, to college age students trying to counter negative perceptions of their culture while sitting in class.

Within each story, students seemed to derive a sense of strength through their response. This was further exemplified by the students who observed that performance 
was a form of resistance by disrupting the perception of Mexican Americans as bad people. Students stated the importance of both maintaining and performing their identity as an affirmation of their culture for themselves and society.

As the students develop a sense of their Community Cultural Wealth, some of their responses also indicated a developing critical consciousness or conscientization (Freire, 1970). Critical consciousness develops when people understand injustice or inequity, see their place within that inequity and take action. Freire believed this happened through a problem posing process that encourages reflection, connection and response to inequity.

As students perform Mexican folk dance, they engage in a problem posing process similar to a dialogue with the audience. Performance of their cultural identity can lead to affirmation or rejection. While experiences with rejection and racism are challenges, the dancers stated their belief that maintaining and performing the connection to culture is important work. The students noted that there are Latino/a people who avoid this dialogue through attempted assimilation into the dominant culture.

The dancers' critical consciousness is evident in their recognition of racism within the world and particularly awareness of racism directed towards them as students who maintain a connection to their culture through dance. Critical consciousness leads to taking action. In the case of these students, performance is an action that disrupts negative perceptions of Mexican Americans. 
Themes from the findings represent how the participants make sense of their experiences within the dance group and at school. Their reflections on these experiences prompt an analysis of structures and belief systems within K-12 schools the present barriers to academic outcomes and engagement for Latino/a students. These barriers will be addressed through a discussion of the implication and recommendations in the next chapter. Through the voices of students performing their cultural identity, teachers and administrators may better understand barriers for Latino/a students as well as the opportunities to promote recognition of their assets through cultural activity. 


\section{Chapter Five: Discussion and Conclusions}

This study was prompted by the problem of inequitable outcomes for Latino/a students in the $\mathrm{K}-12$ setting, and my interest as an educational leader to use the data gathered in this dissertation to enact change. The majority of students in California are Latino/a and there is an increasing gap between the number of Latino/a students who enroll in Advanced Placement classes, graduate from high school and go on to four-year university as compared with their White peers (Darling-Hammond, 2010; McKinsey \& Company, 2009; Radford, et al, 2010). Studies of this achievement gap have surfaced concerns about the representation of Latino/a culture in curriculum, teaching staff and instructional methods (Gay, 2010; Sleeter, 2008). The majority (81.9\%) of teachers are White (NCES, 2010) and this overrepresentation of Whiteness extends to curriculum resources and instructional strategies (Hughes, 2007).

Many schools have put in place systems for providing additional, targeted instruction to Latino/a students. Explanatory studies of these interventions look to make a link between school reform and academic outcomes. This study moves away from an attempt to explain towards an exploration of the experience of students within the dance environment where their culture and language is recognized and affirmed. Using ethnographic methods, data were collected through observation, interviews and focus groups with 16 Latino/a students who have participated in a Mexican folk dance group for at least two years. Dance teachers and the dancers' parents served as additional 
informants. The design of this study supported an exploration of the individual and group identity of students as they shared experiences with dance and at school.

The proposition for this study is that participation in cultural activity leads to developing an ethnic identity and critical consciousness for Latino/a students. This proposition stems from literature on ethnic studies, ethnic identity development and persistence. The research on ethnic studies shows a connection between fostering students' ethnic identity and academic achievement and persistence (Cabrera \& Nolan, 2013; Sleeter, 2012). Similarly, ethnic identity development is closely connected to persistence within and beyond high school (Gibson, 2008). Finally, studies on persistence trace the success of Latino/a students back to membership within a group and mentoring from adults (Burciaga, 2012; Kuh \& Love, 2000; Museus, 2008; Wilson, 2012). These three components are very much present in a folk dance group where students learn about their culture, develop an ethnic identity and connect as a group. This study examines how the Latino/a students participating in folk dance make sense of their experience within the group and at school.

The research questions for this qualitative, exploratory study reflect the theoretical frameworks of Community Cultural Wealth (Yosso, 2005) and Critical Consciousness (Freire, 1970). The first question is: What is the experience of Latino/a student participation in a Mexican folk dance group? This question supported the exploratory design to this study. Students had multiple opportunities to share their experiences and perspective individually and as part of a focus group. 
The second research question is: How does this experience support recognition of their cultural wealth? This question reflects the theoretical framework of Community Cultural Wealth or CCW (Yosso, 2005). Participants were asked to consider the impact of participation in the dance group on recognition of strengths within themselves and their community. The interview and focus group questions drew on the six different areas of strength outlined by CCW. For example, students were asked to share their experience with working in both Spanish and English, which illustrates their linguistic strength. This research question helps connect the study with other research on developing student recognition of their assets.

The final research question moves from exploration to explanation as students describe their experience in two worlds: How do participants make sense of their experiences within the dance group and at school? This question prompts a comparison between the experience with culture-affirming activity outside of school and the academic program during the day. Although this is an exploratory study, the third question prompts educators to examine the ways in which programs at school might draw upon the benefits of cultural activity. This question also surfaced student awareness of how their culture is both affirmed and rejected within the community and at school. The question draws upon the theory of Critical Consciousness as students make note of inequity within their world, the impact on their lives and actions they might take to challenge those structures and beliefs that allow inequity to persist. 


\section{Interpretation of findings}

The research questions guided a study designed to surface how Latino/a students make meaning from their experiences in cultural activity and at school. Through this exploratory study, educators might consider how the arts support students' ethnic identity leading to improved learning outcomes and educational persistence for Latino/a students. The achievement gap for Latino/a students demands a sense of urgency for finding new ways to support Latino/a students by looking outside the constraints of school to the potential in community-based cultural activities such as dance.

Three themes captured the experiences of students in the Mexican folk dance group. Those experiences included exposure to affirmation and rejection as dancers rehearsed and performed their cultural identity. Experiences, both positive and negative, created a strong connection to students' culture and language. The first theme reflected their sense of Community Cultural Wealth (Yosso, 2005). Students shared examples of strengths that ranged from being bilingual to the ability to overcome barriers. The second theme reflects how performance and participation can also lead to indifference or rejection from members of the White and Latino/a communities. As they shared responses to both affirmation and rejection, students spoke of the importance of dance as a way to maintain their culture and challenge the perception of Mexicans as "bad" people. It is this final theme where students showed evidence of conscientization, making a connection to performance of their ethnic identity as an act of challenging racist attitudes. 
In the literature, affirmation of Community Cultural Wealth was cited as an important variable in supporting Latino/a students at high achieving high schools (Lucas et al., 1990; Ostler, 2011; Soto, 2012). In a study of high performing majority Latino schools, school staff had learned about the culture and language of their largely Latino/a student population through home visits, traveling to Mexico and participating in professional development. The core program at several schools featured in these studies had successfully integrated students' language and culture.

Valenzuela (1999) spoke to the importance of culturally affirming activity that counters the implicit and explicit messages students receive throughout their educational experience. The dance group provides affirmation of students' ethnic identity through immersion in the language, culture and customs of Mexico. The participants in this study shared how participation in folk dance both affirmed their identity and made them more aware of how schools, their peers and community may fail to acknowledge or even reject their culture. The affirmation of ethnic identity supports academic achievement and engagement in school (Cabrera, Miller, \& Max, 2012). Students in this study cited high expectations for their work at school and in their futures beyond school. They expressed the impact of the group on helping them to set goals and on providing the support they needed to achieve those goals.

The second theme expands on that sense of indifference or rejection as students shared community response to their performances. Through performance, students were exposed to negative comments as well as lack of acknowledgement that inspired some 
reflection on racism within the community. They defined the dance group as a place where they could put aside the stress they experienced at school. Acculturative stress comes from exposure to or experience with cultural values, practices and language that differ from that of an individual's home culture (Gil, Vega, \& Dimas, 1991). Students in this study defined negative experiences as part of their experience as members of an underrepresented group and as the "Mexicans who dance" performing their cultural identity in the community. In this case, membership within the group was a source of both comfort and rejection.

Studies of persistence within and beyond high school for underrepresented groups point to the importance of group membership (Huber \& Cueva, 2012; Kuh \& Love, 2000; Lucas, Henze, \& Donato, 1990; Soto, 2012). Group members for high school and college students can mitigate the stress that comes from participation in environments that don't acknowledge the students' culture.

The impact of these experiences leads participants to consider performance as a counter-story to combat the negative public opinions of Mexicans and Mexican Americans so prevalent in the press around the presidential election of 2016. The third theme of identity and counter-stories emerged from the overlay of how folk dance allowed students to develop an ethnic identity and an awareness of how society both affirms and rejects their ethnicity. Jasmine's comment about their responsibility to "show other people what our culture is like and that we're not all bad" speaks to the 
tremendous pressure students experience stemming from racist comments towards them and their community.

Perez Huber and Cueva's 2012 study of Latino/a university students included reference to folk dance performance as a way to create a space where students could be proud of their culture and family. One of the students in this study stated that White students' negative responses to their dance performances increased her pride in the work they are doing. Public performances of cultural identity, including parades or athletic events, can allow underrepresented groups to enact their identity in places where they experience discrimination (Quiroz \& Becerra, 2014).

This study contributes to the research on the impact of cultural activity on student outcomes, engagement and persistence. Prior studies that addressed folk dance focused more on the impact of connecting families to school (Wallenstein, 1995). Other studies centered on folk dance measured the impact on affirming students' ethnic identity and engagement. The findings of this study point to the potential for participation in folk dance to support critical consciousness and create a counter-space within schools to promote a strength-based forum for students to collaborate and perform with peers, families, and community members.

The three themes represent the experience of students participating in the folk dance group, the recognition of Community Cultural Wealth (Yosso, 2005) and how these dancers make sense of their experiences in the group and at school. Through their 
voices, this study encourages reflection on the policies, practices and belief systems that facilitate or prevent equitable outcomes for all students.

\section{Implications and recommendations}

The proposition for this study is that schools can close the achievement gap for Latino/a students through supporting the development of an ethnic identity and critical consciousness. Participation in folk dance provided students with many of the tools they need to do both. A connection to their culture and performance of that cultural identity strengthens student understanding of who they are in a racialized society, both affirming that identity and activating resistant capital that potentially allows them to overcome barriers of racism and educational inequality.

\section{Educational Equity}

There are persistent barriers within school systems that prevent Latino/a students from participating in advanced classes or even the required coursework for A-G completion. Participants shared examples of inequity as expressed through lowered expectations, language policies and underrepresentation of their culture within the school environment. Counselors who dissuade students from honors classes, and teachers who don't take time to learn about their students contribute to the problem of inequitable experiences leading to inequitable outcomes.

Educational equity is at the heart of the recommendations for supporting all students. These recommendations reflect what we might learn from the experiences of Latino/a students participating in a folk dance group with a focus on the question: How 
do students make sense of their involvement in the dance group and at school? Participants in this study shared their experience with affirmation and rejection, with discovering their community strengths, and an understanding of who they are in a world where they are underrepresented and misrepresented. In sharing these experiences, it became evident that the folk dance group provides students with access to caring adults, high expectations, the opportunity to develop an ethnic identity and to perform that identity in public.

I argue that these supportive connections to understanding culture create feelings of group membership and a positive ethnic identity that promotes individual and collective growth. The opportunity to perform this dual identity in the dance context leads to critical consciousness that supports student persistence and engagement outside of traditional school structures that privilege Whiteness (see figure 2). Through this outside performance, students develop a critical ethnic identity that helps them to understand and challenge injustice within society (Tintiangco-Cubales et el, 2014). The recommendations that follow draw upon the findings from this study to revision how schools might adapt elements of the students' dance experiences to support a critical ethnic identity and increase engagement, persistence and academic achievement in schools. 


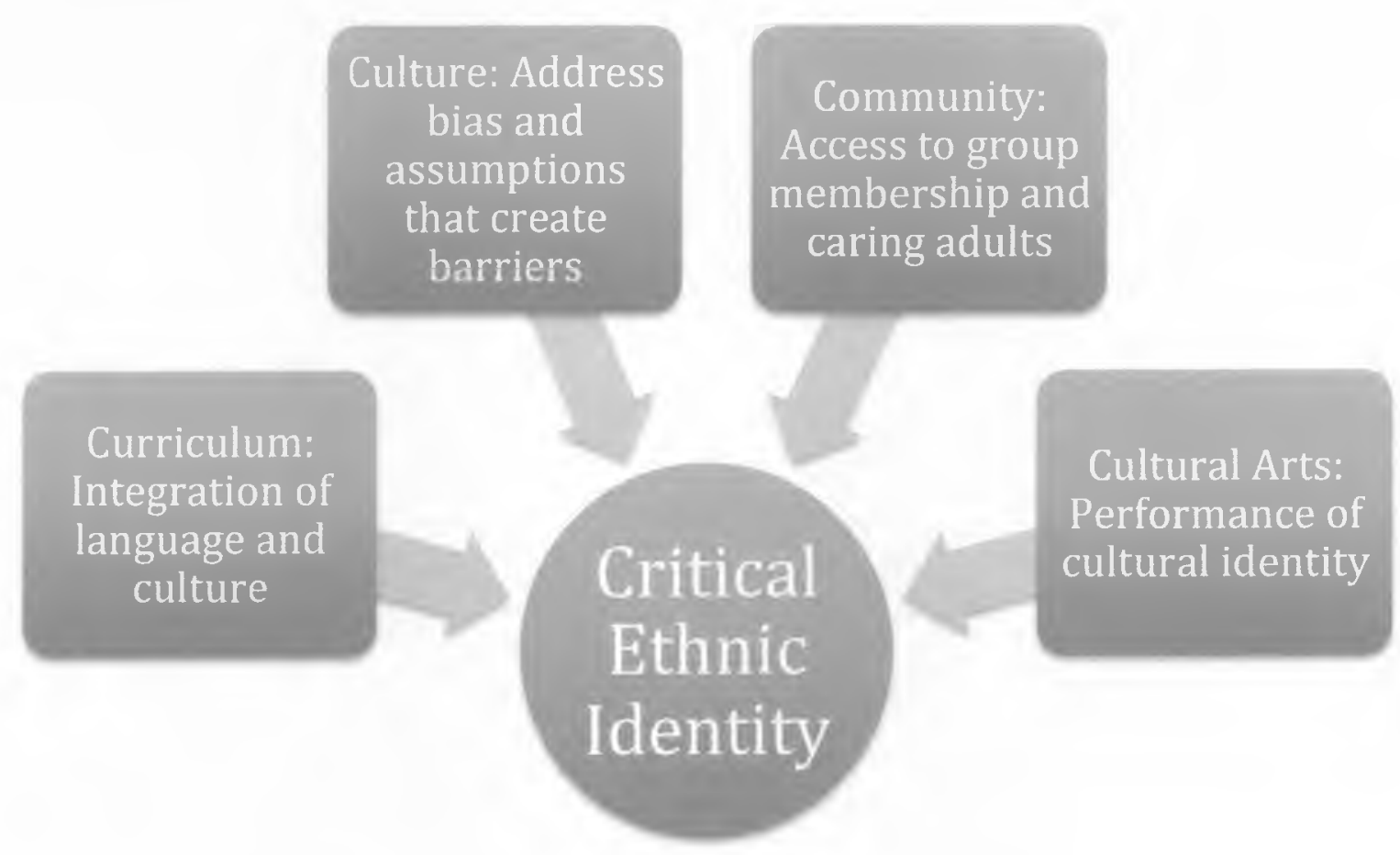

Figure 2. Critical Ethnic Identity

\section{Implications for curriculum and instructional program}

And I think the biggest mistakes that schools make or that schools do is diversity for a day or cultural fair or the world bazaar. Stuff like that, I'm not really happy with because it's a show and our culture isn't a show, our culture isn't a performance. It's not a one-day thing. It's not just our food; it's not just our clothes. It's just so much more than that. (Ana, college) Ana's critique on the token acknowledgement of different cultures in curriculum connects with the concern about cultural missionaries in Mexico in the 30's who provided a superficial introduction to folklórico with a goal of unification. Teaching choreography without context is similar to learning about culture through an isolated 
event with food and music. In both these instances, there is scant attention given to the social and historical contexts that contribute to the artistic expression.

The implications from research on Ethnic Studies and the voices of participants in this study support the recommendation to expand units of study within social studies to include the experiences of Latino/as. Social studies curriculum should include units that explore dance as representative of the history of indigenous people of Mexico and the Mestizo class that developed through colonization. Often indigenous peoples are presented as the victims of colonization rather than through a lens that focuses on the strengths of their culture. Folklórico presents both the cultural strengths and interactions with colonizers through dances that reflect cultural values and historical events.

Curriculum that supports the racial and ethnic identity of Students of Color leads to an increase in academic achievement and engagement in school (Altsbul, Oyserman \& Bybie, 2008). The Mexican American Studies program in Tucson high schools is a model for setting high expectations and connecting students with their culture. Through an ethnic studies' pedagogy, teachers provide students with information about their culture and the role of racism within society. Ethnic studies is designed to provide students with access to quality education that draws upon their experience and strengthens community involvement through advocacy and activism (Tintiangco-Cubales et al, 2014). The studies of student success in the Mexican American Studies (MAS) program indicate an increase in academic performance and persistence beyond high school. Instruction in language arts and history classes entered on Latino/a experiences, with an explicit focus 
on the role of racism in creating barriers and inequitable outcomes. By centering instruction on race and racism, students develop a critical consciousness that allows them to better understand and challenge injustice within society (Tintiangco-Cubales et al., 2014).

Instruction in the folk dance group functions as a form of out-of-school ethnic studies as students learn about and perform their cultural identities. Performance often brings them in contact with racism and the group provides both a source of comfort and the inspiration to speak out against racism. The dancers in this study had a strong understanding of how the choreography, clothing and props represented historical events and cultural ways of being. This knowledge gave them a stronger connection to their ethnic identity that replicates the outcomes seen in the analysis of MAS program in Tucson.

Schools along the border of Texas and Mexico have begun to bring Baile Folklorico in to the physical education offerings. Several schools have also included Mariachi in band classes in Texas and in San Francisco. Through curriculum that represents students' culture, schools can support the development of ethnic identity for Latino/a students and increase their engagement in schools

The research and student voice support increased access to ethnic studies curriculum. In California, only 17 of 1,000 districts currently offer an ethnic studies course, even though the courses are approved for elective credit at both UC and CSU (Ed 
Source May, 2016). Representative Luis Alejo sponsored AB2016 that states all high schools should be encouraged to offer a standards-based ethnic studies curriculum.

Local school districts may set additional graduation requirements to those set by the state. Los Angeles Unified School District has voted to make Ethnic Studies a mandatory graduation requirement. The only dissension to this proposal came from their superintendent who cautioned against the additional expense. At the state level, Governor Jerry Brown has vetoed legislation to promote ethnic studies curriculum stating that curriculum is reviewed through the Instructional Quality Commission implying that proposals for new courses should only come through this organization

As teachers are facilitating a study of the impact of race and racism, they must also participate in a reflection of their identity and role within a racialized society (Tatum, 1992). Sleeter (2012) pointed out that this is more difficult for White teachers as they often do not think in terms of race. The White teachers experience with privilege may present a barrier to their ability to engage in the type of critical reflection that supports ethnic studies pedagogy.

Recommendation 1: Revise existing social studies and physical education courses offered through the district to reflect the contributions of Latino/a culture and arts

With the new social studies framework adoption in fall 2016, there are opportunities for districts to procure new resources and align units with new standards. Districts may convene committees to review and adopt new texts that support these standards. Prior to the adoption process, it is recommended that the district send the 
committee to review the existing Ethnic Studies curriculum in San Francisco Unified School District. Consideration should be given to visiting Ethnic Studies classes and interviewing teachers and students about what is working well. As the committee develops course proposals, they should share their drafts with members of Latino/a community groups and students. Through this process, course development may more accurately reflect both the history and the lived experience of the Latino/a group. This district could begin by adding an Ethnic Studies course to high school that and then look to create vertical articulation through Social Studies units beginning in kindergarten.

Pues, en México, yo estuve en México hasta séptimo grado, es un arte entonces incluyen en el currículo tienes que tomar unas clases de arte entonces pintura lo que ofrezcan so mi maestro que tenia eso es lo único que sabe que hacer [In Mexico, when I was in $7^{\text {th }}$ grade, folklórico was considered an art, like painting, so my teacher was the one who taught us] (Maribel, dance teacher).

Maribel learned folklórico through art classes at her school in Mexico. Dance instruction in this district has been supported through enrichment classes in elementary with very little available to secondary students. Physical education standards support dance instruction. These standards have been overlooked in courses that focus on team and individual sports. The current physical education programs in this district do not include dance instruction. There is an opportunity again to learn from neighboring districts and perhaps draw on the experience of the dance group to include folklórico in 
physical education classes. As with any course of study, it would be important to find a teacher with appropriate experience and background. In the early part of the $20^{\text {th }}$ century, American teachers taught La Raspa or the Mexican Hat Dance, which did little to connect Latino/a students with their culture. The district may develop a consultant services agreement with professional experts in the area of folklorico to teach units within existing physical education classes.

Recommendation 2: Develop a strong, research-based biliteracy programs in the district's K-12 schools and create a district task force to develop a Biliteracy Master Plan to expand and improve upon existing bilingual/biliteracy programs in elementary through secondary

Sometimes right away we are asking one of our friends a question and instead of asking them in English it comes out in Spanish and the teacher is like 'What did you guys say?' We just asked them for like something. 'No you guys are talking about this person and I'm going to give you detention if you do that again' (middle school focus group).

Ever since I was little my family has told me to embrace that because I'm very lucky to be able to speak two languages. And that it would benefit me later in life and so I'm always really grateful to be able to speak two languages, one because in school it helps me sometime with the vocabulary because I can relate to things (Flor, high school) 
Many students shared that their bilingual and biliteracy skills were supported through the dance group but not at school. Proposition 227 eliminated bilingual programs in California sending a strong message that assimilation and monolingual skills were desired over acculturation and biliteracy. This legislation countered research that illustrated the impact of biliteracy on greater academic outcomes. With the overturn of proposition 227 in January 2016, educational leaders have an opportunity to right a wrong.

The California Multilingual Education Act for a $21^{\text {st }}$ Century Economy was signed in to law January 2016. This act repeals the provisions of Proposition 227 that required parents of English Learners to sign waivers in order to enroll in bilingual programs and that required English Only instruction for students learning English as their second language. In addition, the act requires schools district to solicit input from parents of English learners as they design programs to support their engagement and learning.

The new state legislation provides guidelines for this work that should include all stakeholders, particularly parents of English Learners. Board policy creates the framework and can establish a task force that is charged with developing a bilingual education plan. This plan should include curriculum development, teacher training, hiring and evaluation practices, and student assessment protocols. The task force should begin with an assessment of current bilingual and biliteracy programs; examining student achievement and participation data. From this data and observations of other model 
biliteracy programs, the task force may create a list of recommendations in each of the aforementioned areas.

\section{Implications for developing school culture through professional development}

Student responses illustrated the rejection they experience through performing their ethnic identity both from White and Latino/a communities. They also shared frustration that teachers did not always address the racist comments in class. In addition to racist comments, students were frustrated that they were often the only Latino/as in more advanced classes and described the difficult conversations they had with counselors in order to be placed in those classes.

It's another thing for me to feel uncomfortable because I know that walking in to any of my math classes I'm going to be the only Latina there, but that's something that I've also been used because even in middle school when I started there taking Algebra and Geometry I was the only Latina there, so that's something that I it hurt me before. I still notice it, so maybe that means that it still hurts me. (Ana, college)

Ana's reflection, as a college student, should give a sense of urgency to counselors, administrators and teachers. The barriers that lead to disproportionate number of Latino/a students in lower tracked classes include lowered expectations as well as structures that prevent access. The recommendations below address the need for training and reviewing those structures. 
Recommendation 3: Provide professional development for counselors and school staff that helps surface the bias and assumptions they bring to their work.

This recommendation recognizes that attitudes and belief systems are often what influence inequitable systems or structures. These belief systems must be addressed prior to setting new goals or the system will revert back to one that privileges one group over another. Culturally relevant professional development for counselors should help them to identify the impact of their experiences and belief systems on their approach to working with Latino/a students. This professional development should include an opportunity for counselors to hear from students, perhaps in a fishbowl setting where students talk together and counselors listen before asking clarifying questions. Through the professional development process, counselors could then set goals for their work to increase the number of Latino/a students enrolled in advanced classes.

Professional development for administrators and teachers could focus on supporting their ability to talk about race and racism with students. Several examples that came out of this study illustrate that teachers did not have the skills to respond when there were racialized comments in the classroom. Derald Wing Sue wrote about this in Race Talk: The Psychology of Racial Dialogues (2013). He describes classrooms where teachers remain silent out of a sense of not knowing how best to respond to racialized commentary from students. Sue has three recommendations to address this silence and effectively engage in racial dialogue that supports all students. The first recommendation is to not remain silent or passive. This was the response of Cecilia's professor when 
another student made a negative reference to Mexicans in the news. Cecilia was disappointed that she was the only one to respond and wished that the professor had said something. The second recommendation is for teachers to acknowledge their own bias and assumptions. This creates a culture in which others may acknowledge their failings. The final recommendation is to facilitate a discussion of feelings. In Sue's study, Students of Color reported that in classes where the professor encouraged them to share their feelings, they felt supported when talking about race.

These recommendations should be the basis for professional development that supports school staff. The first step in training is to identity their bias and assumptions. From there, staff may learn strategies for supporting students in class and increasing the number of underrepresented students in advanced courses.

Recommendation 4: Set goals with school staff for increasing the number of underrepresented students in advanced classes.

Setting goals to close the achievement gap is the next step following training on bias and assumptions. Through setting goals, school staff can measure the impact of programs, resources and services on increasing access for all students. This recommendation prompts the staff to use disaggregated data, drilling down to our student subgroups and make note of progress. Through monitoring the data, staff may begin to identify the barriers to access and to successful completion of coursework. It is not enough to simply place underrepresented students in classes. Teachers will need to identify different instructional approaches that work best for a diverse group of students. 
The purpose of setting goals thus is both to increase student access and to identify best strategies for sustaining their success.

\section{Implications for community and school partnership}

The dance environment creates a place where students can make a connection to their culture and each other. Caring adults provide wrap around services in addition to dance instruction. Schools can learn from this example by increasing opportunities for students to develop a group identity and for staff to provide additional resources. There are very few opportunities for students to build an ethnic identity within school. At the three comprehensive high schools, there is one Latino club and a multicultural club. From the literature, we know that ethnic group associations can support student persistence and engagement in school. Examples from the literature highlight how organizations such as Migrant Student Association (Gibson, 2002) and other less formal community partnerships provide students with a "human bridge" (Stanton-Salazar, 2001) that build community and support persistence.

Recommendation 5: Develop partnership with community based organizations at each of the district's three high schools to support ethnic identity development

The district should create a Memorandum of Understanding, with community partners providing them with a space on campus where students could meet during the school day. This space would serve the purpose of both supporting students and increasing awareness of the diversity of culture and language at school. In addition, the community partners should have access to campus outside of the day to support evening 
events that included students' families. This recommendation expands upon the relationship between district and the dance group currently, setting a goal for increasing support from the district for this and other community partnerships.

Through this partnership, the district may also develop staff recognition of the community organization. Students in this study shared their disappointment that many teachers did not attend their performances and did not provide opportunities for them to share their experiences. A more formal partnership between district and community organization might lead to greater awareness on the part of school staff that would support students as they develop their identity through performance.

\section{Implications for arts-based instruction during the school day}

Dance practice for participants takes place outside of the school day requiring a tremendous commitment on the part of parents and community to provide transportation and negotiate around school commitments including homework. Not all students can participate which contributes to another gap in the experience of Latino/a students in our district.

The placement of this activity outside of school also creates a disconnect between school personnel and their knowledge of students' culture. Two of our middle school teachers went with me to a performance last December and shared how much this performance shifted their understanding of their students and their culture. One teacher confided that she now saw those students differently, as more confident and capable. 
Through the generosity of local parcel taxes, our district is able to support instruction in visual art and instrumental music for all students in grades TK-8. High school students may take art or music as an elective. Although $45 \%$ of the district student population are Latino/a, there are very few references to their culture in the arts program. For students in this folk dance group this is not dancing just for the sake of dancing. Participation is a connection to their culture through the arts that increases their knowledge and pride in their ethnicities. To close the achievement gap for Latino/a students, our district should provide students with the opportunities to connect with their culture through the arts and performing their cultural identity as part of the school day. Recommendation 6: Increase access to cultural arts in school.

The district should develop a framework for the development of cultural arts instruction across all grade levels. This framework could provide an outline for introducing students to different forms of cultural art including instrumental music, visual arts and dance. As the structures are already in place to provide students with visual and performing arts instruction, this framework could support the integration of cultural arts during the school day.

Cultural arts should be taught by instructors who have a strong background in both the culture and the art form. This will necessitate hiring additional staff some of whom may have a different set of credentials and experience than those recognized by the California Teaching Commission (CTC). The district may need to work with the union 
and the CTC to create opportunities for these "professional experts" to provide instruction.

In addition to instruction in cultural arts, it is important to provide students with the opportunity perform. The district could include these performances as part of their annual music concert, at open house events and back to school night. Currently, the students in this dance group are asked to perform for Cinco de Mayo celebrations. By inviting their performance at district events throughout the year, the district would begin to communicate that cultural arts, like the cultural identities of our students, should be placed at the center and not relegated to holidays.

\section{Recommendations for further study}

This study was purely qualitative, relying solely on student voice to illustrate the impact of their experience in a folk dance group. A longitudinal study of the same group that included outcome data may strengthen the argument that participation in cultural activity can lead to persistence. Outcome data could include academic achievement as measured by local and state assessments. Measures of student engagement could look at participation in school including college.

Further research might also examine a control group with matched demographics and experience who did not participate in the dance group. This study might reveal other variables to student success than the ones that surfaced through a study of students in folk

dance. Through studying a group that is not involved in folk dance, we might also learn about other ways students connect with their culture. 


\section{Reflection on research process}

I began this process thinking I would find ways to translate the students' experience to the classroom. I assumed that participation in dance was affirming and in my ignorance thought that schools could tap in to this culture affirming activity throughout the day. I had no idea that performance set students up to be targets within the Latino/a and White communities. However, through their stories of indifference, rejection and racism, students never presented themselves or the group as victims. Their responses to overt negativity mirrored their response to affirmation. In both contexts, students expressed pride in their culture. Within a context of affirmation, students expressed a sense of responsibility to be authentic for those who knew the culture. Within the context of racism, students felt responsible for countering prejudice based on ignorance.

I was surprised that students as young as 13 were making connections between their participation and larger issues of discrimination. Their stories of being bullied were shared alongside a desire to combat the reputation of Mexicans as "rapists" or "terrorists". The conceptual framework I had created underwent several changes as I reviewed the data. The last theme; Identity and Counter-Stories came out of focus group discussions where students shared stories that represented a strong ethnic identity and resistant capital. 


\section{Conclusion}

The students in this study shared their experiences with culture affirming activity that may prove to be instructive for educators as we look at the barriers creating an achievement gap for Latino/a students. Through the folk dance group, students had the opportunity to develop an ethnic identity and perform that identity. Performance resulted in both affirmation and rejection from the community that led to a more critical ethnic identity. This critical ethnic identity in students comes from an understanding of who they are, racism in their environment and the ability to address racism through performance.

Students in the folk dance group have created a counter-story to the one told by standardized assessment data. They experience success through an environment characterized by high-expectations and care. As educators, we can learn from this example as we look to provide all students with access to knowledge of their ethnic identity, rigorous curriculum, group membership and caring adults. 


\section{References}

Altschul, I., Oyserman, D., \& Bybee, D. (2008). Racial-ethnic self-schemas and segmented assimilation: Identity and the academic achievement of Hispanic youth. Social Psychology Quarterly, 71(3), 302-320.

Baker, C., \& Jones, S. P. (Eds.). (1998). Encyclopedia of bilingualism and bilingual education. Multilingual Matters.

Ballard, K. R. (2002). Mariachi: Ethnic Music as a Teaching Tool. Teaching Music, 9(4), $22-27$.

Barba, M. B., \& Soto, A. (2007). Enriching or endangering: Exploring the positive and negative effects on recontextualizing Mariachi music for use in $\mathrm{K}-12$ schools. Musike. International Journal of Ethnomusicological Studies, 1(3).

Becerra, M. V. Q. (2014). Performing Belonging in Public Space Mexican Migrants in New York City. Politics \& Society, 42(3), 331-357.

Bourdieu, P. (1977). Outline of a theory of practice (Vol. 16). Cambridge University Press.

Braxton, J. M., Shaw Sullivan, A. V., \& Johnson, R. M. (1997). Appraising Tinto's theory of college student departure. Higher Education-New York-Agathon Press Incorporated -12 (1997): 107-164.

Cabrera, N. L., Milem, J. F., Jaquette, O., \& Marx, R. W. (2014). Missing the (Student Achievement) Forest for All the (Political) Trees Empiricism and the Mexican 
American Studies Controversy in Tucson. American Educational Research Journal, 5l(6), 1084-1118.

California Department of Education (2014a). Educational Demographics Unit. Retrieved from http://dq/cde.ca.gov/dataquest/California Department of Education (2014b). Dropout Rate. Retrieved from http://dq/cde.ca.gov/dataquest/ Cammarota, J., \& Romero, A. (2006). A Critically Compassionate Intellectualism for Latino/a Students. Multicultural Education, 14(2), 16-23.

Cerezo, A., \& Chang, T. (2013). Latina/o Achievement at Predominantly White Universities The Importance of Culture and Ethnic Community. Journal of Hispanic Higher Education, 12(1), 72-85

Collier, V., \& Ovando, C. (1998). Bilingual and ESL classrooms: Teaching in multicultural contexts.

Clark, V. L. P., \& Creswell, J. W. (2008). The mixed methods reader. Sage.

Cummins, J. (1991). Interdependence of first-and second-language proficiency in bilingual children. Language processing in bilingual children, 70-89.

Cruz Valle, N. Danza folklórica, herramienta, educativa para la formación integral de los niños. Revista de Educación y Cultura de la Sección 47 del SNTE/Jalisco. 20,146151.

Darling-Hammond, L. (2010). Teacher education and the American future. Journal of teacher education, 61(1-2), 35-47. 
Delgado Bernal, D., Burciaga, R., \& Flores Carmona, J. (2012). Chicana/Latina testimonios: Mapping the methodological, pedagogical, and political. Equity \& excellence in education, 45(3), 363-372

Norman K. Denzin, \& Yvonna S. Lincoln. (2005). The Sage handbook of qualitative research. Sage.

Diemer, M. A., \& Li, C. H. (2011). Critical consciousness development and political participation among marginalized youth. Child Development, 82(6), 1815-1833.

Feay-Shaw, S. (2002). The music of Mexican-Americans: A historical perspective of a forgotten culture in American music education. Journal of Historical Research in Music Education, 24(1), 83-102.

Freire, P. (1970). Pedagogy of the Oppressed, trans. Myra Bergman Ramos. New York: Continuum.

Gándara, P., \& Hopkins, M. (2010). English learners and restrictive language policies. New York, Columbia University, Teachers College.

Gay, G. (2010). Culturally responsive teaching: Theory, research, and practice. Teachers College Press.

Gay, G. (2012). Our Children Need..."Education for Resistance”. Journal of Educational Controversy, 6(1), 8 .

Gibson, M. A., \& Bejinez, L. F. (2002). Dropout prevention: How migrant education supports Mexican youth. Journal of Latino/as and Education, 1(3), 155-175 
Gil, A. G., Vega, W. A., \& Dimas, J. M. (1994). Acculturative stress and personal adjustment among Hispanic adolescent boys. Journal of Community Psychology, 22(1), 43-54.

Glaser, B. G., Strauss, A. L., \& Strutzel, E. (1968). The Discovery of Grounded Theory; Strategies for Qualitative Research. Nursing Research, 17(4), 364.

Gustafson, S. L. (2004). El Espiritu de Aztlan.

Hakuta, K. (1986). Mirror of language: The debate on bilingualism. Basic Books.

Harris, D. M., \& Kiyama, J. M. (2013). The role of school and community-based programs in aiding Latina/o high school persistence. Education and Urban Society, 0013124513495274.

Hellier-Tinoco, R. (2005). Becoming-in-the-world-with-others: Inter-Act Theatre Workshop. Research in drama education, 10(2), 159-173.

Hipolito-Delgado, C. P., \& Zion, S. (2015). Igniting the Fire Within Marginalized Youth The Role of Critical Civic Inquiry in Fostering Ethnic Identity and Civic SelfEfficacy. Urban Education, 0042085915574524.

Horne, T. (2007). An open letter to the citizens of Tucson. Tom Horne for Attorney General, 11 .

Hu-DeHart, E. (1993). The history, development, and future of ethnic studies. Phi Delta Kappan, 75(1), 50. 
Huber, L. P., \& Cueva, B. M. (2012). Chicana/Latina testimonios on effects and responses to microaggressions. Equity \& Excellence in Education, 45(3), 392410.

Hughes, R. L. (2007). A hint of whiteness: History textbooks and social construction of race in the wake of the sixties. The Social Studies, 98(5), 201-208.

Hurtado, S., \& Carter, D. F. (1997). Effects of college transition and perceptions of the campus racial climate on Latino/a college students' sense of belonging. Sociology of education, 324-345.

Jayakumar, U., Vue, R., \& Allen, W. (2013). Pathways to college for Young Black Scholars: A community cultural wealth perspective. Harvard Educational Review, 83(4), 551-579.

Joseph, G. M., Rubenstein, A., \& Zolov, E. (2001). Fragments of a golden age: The politics of culture in Mexico since 1940. Duke University Press.

Kuh, G. D., \& Love, P. G. (2000). A cultural perspective on student departure. Reworking the student departure puzzle, 1, 196-212

Ladson-Billings, G. (1995). Toward a theory of culturally relevant pedagogy. American educational research journal, 32(3), 465-491.

Lewis, K. M., Sullivan, C. M., \& Bybee, D. (2006). An experimental evaluation of a school-based emancipatory intervention to promote African American well-being and youth leadership. Journal of Black Psychology, 32(1), 3-28. 
Lipka, J., \& Adams, B. (2004). Culturally Based Math Education as a Way to Improve Alaska Native Students' Math Performance. Appalachian Collaborative Center for Learning.

Locke, L. A., \& Blankenship, A. E. (2015). Keeping the Flames at Bay: The Interplay between Federal Oversight and State Politics in Tucson's Mexican American Studies Program. Journal of Educational Controversy, 10(1), 2.

Liou, D. D., \& Rojas, L. Teaching for Empowerment and Excellence: The Transformative Potential of Teacher Expectations in an Urban Latina/o Classroom. The Urban Review, 1-23.

Lucas, T., Henze, R., \& Donato, R. (1990). Promoting the success of Latino/a languageminority students: An exploratory study of six high schools. Harvard Educational Review, 60(3), 315-341.

Lucas, T., \& Villegas, A. M. (2013). Preparing linguistically responsive teachers: Laying the foundation in preservice teacher education. Theory Into Practice, 52(2), 98109.

Lucas, T., Henze, R., \& Donato, R. (1990). Promoting the success of Latino/a LanguageMinority students: An exploratory study of six high schools. Harvard Educational Review, 60(3).

Martinez, T. V. Mexican Baile Folklórico: Dancing with Empire and Expressing the Nation. 
McClain, M. (2004). Folklore Dance Groups as Learning Environments: A Mexican American Folklorico Example. ARTS AND LEARNING RESEARCH, $20(1), 39$.

McKinsey \& Company. (2009). The economic impact of the achievement gap in America's schools. New York, NY: Author Merriam, S. B. (2014). Qualitative research: A guide to design and implementation. John Wiley \& Sons.

Mexico-Indigenous People (2016). Retrieved from http://minorityrights.org/

Miles, M. B., Huberman, A. M., \& Saldaña, J. (2013). Qualitative data analysis: A methods sourcebook. SAGE Publications, Incorporated

Moll, L. C.; Amanti, C.; Neff, D.; Gonzalez, N. (1992). Funds of knowledge for teaching: Using a qualitative approach to connect homes and classrooms. Theory into Practice, XXXI (2).

Museus, S. D. (2008). The role of ethnic student organizations in fostering African American and Asian American students' cultural adjustment and membership at predominantly White institutions. Journal of College Student Development, 49(6), 568-586.

Nagel, J. (1994). Constructing ethnicity: Creating and recreating ethnic identity and culture.

Nájera-Ramírez, O. (1989). Social and political dimensions of folklórico dance: The binational dialectic of residual and emergent culture. Western Folklore, 48(1), 15 32. 
Nájera-Ramírez, O. Ballet Folklórico Mexicano: Choreographing National Identity in a Transnational Context. Dancing Cultures: Globalization, Tourism and Identity in the Anthropology of Dance, 4, 161

NCES, U.S. Department of Education. Institute of Education Sciences, National Center for Education Statistics. 2010

Ostler, M. (2011). Baile Folklorico De Durango: Initiating Cultural Transmission Through Performance

Ovando, C. J. (2003). Bilingual education in the United States: Historical development and current issues. Bilingual research journal, 27(1), 1-24.

Perez Huber, L., \& Cueva, B. M. (2012). Chicana/Latina testimonios on Effects and Responses to Microaggressions. Equity and Excellence in Education, 45(3), 394-4

Radford, A. W., Berkner, L., Wheeless, S., \& Shepherd, B. (2010). Persistence and attainment of 2003-04 beginning postsecondary students: After 6 years (NCES 2011 -151). U.S. Department of Education. National Center for Education Statistics. http://dx.doi.org/http://nces.ed.gov/pubsearch/

Reti, I. H., Zepeda, S., \& Nájera-Ramírez, O. (2014). Crossing Borders, Crossing Worlds: An Oral History with UC Santa Cruz Professor Olga Nájera-Ramírez.

Rodriguez, R. (2009). Folklórico in the United States: Cultural Preservation and Disillusion. Dancing Across Borders: Danzas y Bailes Mexicanos, 335-358.

Rogler, L. H., Cooney, R. S., \& Ortiz, V. (1980). Intergenerational change in ethnic identity in the Puerto Rican family. International Migration Review, 193-214. 
Rumbaut, R. G. (1994). The crucible within: Ethnic identity, self-esteem, and segmented assimilation among children of immigrants. International Migration Review, 748794.

Scott, J., Trujillo, T., \& Rivera, M. D. (2016). Reframing Teach for America: A Conceptual Framework for the Next Generation of Scholarship. education policy analysis archives, 24(12), n12.

Sheets, R. H. (1995). From Remedial to Gifted: Effects of Culturally Centered Pedagogy. Theory into Practice, 34(3), 186-193. Retrieved from http://www.jstor.org/stable/1476638

Sleeter, C. E. (2002). State curriculum standards and the shaping of student consciousness. Social Justice, $29(4$ (90), 8-25.

Sleeter, C., \& Thao, Y. (2007). Guest editors' introduction: Diversifying the teaching force. Teacher Education Quarterly, 3-8.

Sleeter, C. E., \& Grant, C. A. (2008). Making choices for multicultural education: Five approaches to race, class, and gender. John Wiley \& Sons Inc.

Sleeter, C. E. (2011). The Academic and Social Value of Ethnic Studies: A Research Review. National Education Association Research Department.

Sleeter, C. E. (2012). Confronting the marginalization of culturally responsive pedagogy. Urban Education, 47(3), 562-584.

Soto, L. (2012). On becoming Mexican in Napa: Mexican immigrant girls negotiating challenges to transnational identities. Social Identities, 18(1), 19-37. 
Stanton-Salazar, R. D. (2001). Manufacturing hope and despair: The school and kin support networks of US-Mexican youth. Teachers College Press.

Sugarman, S. D., \& Widess, E. G. (1974). Equal protection for non-English-speaking school children: Lau v. Nichols. California Law Review, 62(1), 157-182.

Tajfel, H. (1981). Human groups and social categories: Studies in social psychology. CUP Archive.

Tintiangco-Cubales, A. (2012). ARC of Ethnic Studies. In Ethnic Studies Assembly meeting, San Francisco, $C A$.

Tintiangco-Cubales, A., Kohli, R., Sacramento, J., Henning, N., Agarwal-Rangnath, R., \& Sleeter, C. (2014). Toward an ethnic studies pedagogy: Implications for K-12 schools from the research. The Urban Review, 47(1), 104-125.

Tinto, V. (1993). Building Community. Liberal Education, 79(4), 16-21.

Trujillo, L. A. (1981). Enhancement of Self-Concept and Academic Achievement through Ethnic Dance.

Valenzuela, A. (1999). Subtractive schooling: Issues of caring in education of USMexican youth. State University of New York Press.

Umaña-Taylor, A. J., Gonzales-Backen, M. A., \& Guimond, A. B. (2009). Latino/a Adolescents' Ethnic Identity: Is there a Development Progression and Does Growth in Ethnic Identity Predict Growth in Self-Esteem? Child development, $80(2), 391-405$.

Nicholas Cruz Valle 
Wallenstein, R.. (2012). Educating Students of Poverty: One School's Story. Schools: Studies in Education, 9(2), 160-175. http://doi.org/10.1086/667913

Wiggan, G. (2007). Race, school achievement, and educational inequality: Toward a student-based inquiry perspective. Review of Educational Research, 77(3), 310333.

Williams, C. L., \& Berry, J. W. (1991). Primary prevention of acculturative stress among refugees: application of psychological theory and practice. American psychologist, 46(6), 632 .

Wilson, J. C. (2012). Persistence of Latino/a students in community colleges: an empowerment model addressing acculturative stress.

Yoon, B. (2008). Uninvited Guests: The Influence of Teachers' Roles and Pedagogies on the Positioning of English Language Learners in the Regular Classroom American Educational Research Journal, 45(2)

Yosso, T. J. (2005). Whose culture has capital? A critical race theory discussion of community cultural wealth. Race Ethnicity and Education, 8(1), 69-91 Yosso \& Garcia, 2007 


\section{APPENDIX}

\section{Appendix A: Interview Questions}

Community Cultural Wealth coding:

$A=$ aspirational

$\mathrm{F}=$ familial

$\mathrm{L}=$ linguistic

$\mathrm{N}=$ navigational

$\mathrm{S}=$ social

$\mathrm{R}=$ Resistant

\section{High School Student interview questions:}

1. How did you become involved with the dance group? (S)

2. Does anyone in your family have experience with Mexican dance? (F)

3. What are some of your favorite dances? Why are they your favorite? (S)

4. The practices are conducted in Spanish while your classes in high school are mostly in English. What has been your experience with participating in both environments? (L)

5. What are some of the benefits or challenges of being part of this group? $(S, R)$

6. What have you learned about the culture of Mexico from participating in dance? $(\mathrm{F}$, S)

7. How is practice different or similar to classes in school? (S)

8. How would you define yourself? American, Mexican-American, Latino/a? (F)

9. Tell me about your plans after high school graduation. (A)

10. What or who will help you to achieve your goal (s)? (N, F, S) 


\section{Focus group questions: High School}

1. Tell me about the dance community. How would you describe your group to an outsider? (S)

2. Do your teachers and other students in high school know that you participate in dance? (S) What are the opportunities for you and others to share this experience?

3. How would you describe Baile Folklorico to someone who has no knowledge or experience with this form of dance? (S)

4. Dance performances allow an audience to learn about different indigenous cultures in Mexico. What are some other ways that Mexican culture is represented in your high school? (R)

5. How is dance practice similar to or different from your experience in high school classes? $(\mathrm{S}, \mathrm{N})$

6. How is your dance class instructor similar to or different from teachers in your high school? (S, R)

7. What are the characteristics of someone who is a strong dancer? How can you tell that they have talent or skill? (S, R)

8. Would you recommend Baile to other students? If yes, who would you recommend participate and why? If no, why wouldn't you recommend this form of dance? $(\mathrm{N}, \mathrm{S})$

\section{Middle School Interview Questions}

1. When did you start dancing with this group? Did you have any friends who were in the group? How did you come to be a part of the group? (S)

2. Does anyone in your family have experience with baile? Your mom, dad, cousins? (F)

3. What are some of your favorite dances? Why are they your favorite? (S) 
4. The dance teacher speaks mostly in Spanish while your classes in middle school are mostly in English. Do you feel comfortable with both English and Spanish? (L)

5. What do you like about being in dance and what do you dislike? $(S, R)$

6. What have you learned about the culture of Mexico from participating in baile? (F, S)

Question 7 from high school was removed

8. How would you define yourself? American, Mexican-American, Latino/a? (F)

9. Tell me about your plans after high school graduation. (A)

10. What or who will help you to achieve your goal (s)? (N, F, S)

\section{Focus group questions: Middle School}

1. Tell me about the Baile group. How is your group the same as and different from other groups at your school? (S)

2. Do the teachers and other students in your school know that you participate in Baile?

(S) What are the opportunities for you and others to share this experience?

3. How would you describe Baile Folklorico to someone who has no knowledge or experience with this form of dance? (S)

4. What are some other ways that Mexican culture is represented in your middle school? (R)

Removed question 5 from high school focus group

6. How is your dance class instructor similar to or different from teachers in your middle school? (S, R)

7. What are the characteristics of someone who is a strong dancer? How can you tell that they have talent or skill? $(\mathrm{S}, \mathrm{R})$ 
8. Would you recommend this form of dance to other students? If yes, who would you recommend participate and why? If no, why wouldn't you recommend this dance group?

$(\mathrm{N}, \mathrm{S})$

\section{College Student interview questions:}

1. How did you become involved with this dance group? (S)

2. Does anyone in your family have experience with this form of dance? (F)

3. What are some of your favorite dances? Why are they your favorite? (S)

4. The practices are conducted in Spanish and your college classes are mostly in English. What has been your experience with participating in both environments?

5. What are some of the benefits or challenges of being part of this group? (S, R)

6. What have you learned about the culture of Mexico from participating in the dance group? (F, S)

7. How do manage practice within your school/work schedules? (S)

8. How would you define yourself? American, Mexican-American, Latino/a? (F)

9. Tell me about your plans after college? (A)

10. What or who will help you to achieve your goal (s)? (N, F, S)

\section{Focus group questions: College}

1. Tell me about the Baile community. How would you describe your group to an outsider? (S)

2. Do your professors and other students know that you participate in Baile? (S) What are the opportunities for you and others to share this experience?

3. How would you describe Baile Folklorico to someone who has no knowledge or experience with this form of dance? (S) 
4. Baile folklorico performances allow an audience to learn about different indigenous cultures in Mexico. What are some other ways that Mexican culture was represented in your high school or in your college? (R)

Question 5 from high school omitted

6. How is your Baile class instructor similar to or different from other teachers in your high school or college experience? (S, R)

7. What are the characteristics of someone who is a strong dancer? How can you tell that they have talent or skill? (S, R)

8. Would you recommend Baile to other students? If yes, who would you recommend participate and why? If no, why wouldn't you recommend Baile? $(\mathrm{N}, \mathrm{S})$

Questions for Baile instructors

1. How many year have you been involved with Baile folklorico and how?

2. What was your experience and training that lead you to be an instructor?

3. How would you define the dances you teach students?

4. How would you describe the group of dancers with whom you work?

5. How would you describe the environment of dance practice? How is this environment similar to or different from other school environments?

6. What do you hope your students will gain from participating in dance?

7. What would you like school administrators and teachers to know about Baile folklorico? 